\title{
Complex Wounds in Patients Receiving Hemodialysis
}

\author{
Masaki Fujioka \\ Department of Plastic and Reconstructive Surgery, Clinical Research Center \\ National Hospital Organization Nagasaki Medical Center \\ Japan
}

\section{Introduction}

Patients receiving hemodialysis (HD) often have complex chronic wounds, which are hard to heal because of complications of other diseases, including DM, calciphylaxis, collagen disease, arteriosclerosis obliterans, chronic anemia, and weakness of the skin (Figures 1-3)1-3). Subsequent infection of necrotic skin tissue is associated with the risk of sepsis, which may be fatal if the blood access shunts become infected ${ }^{4}$.

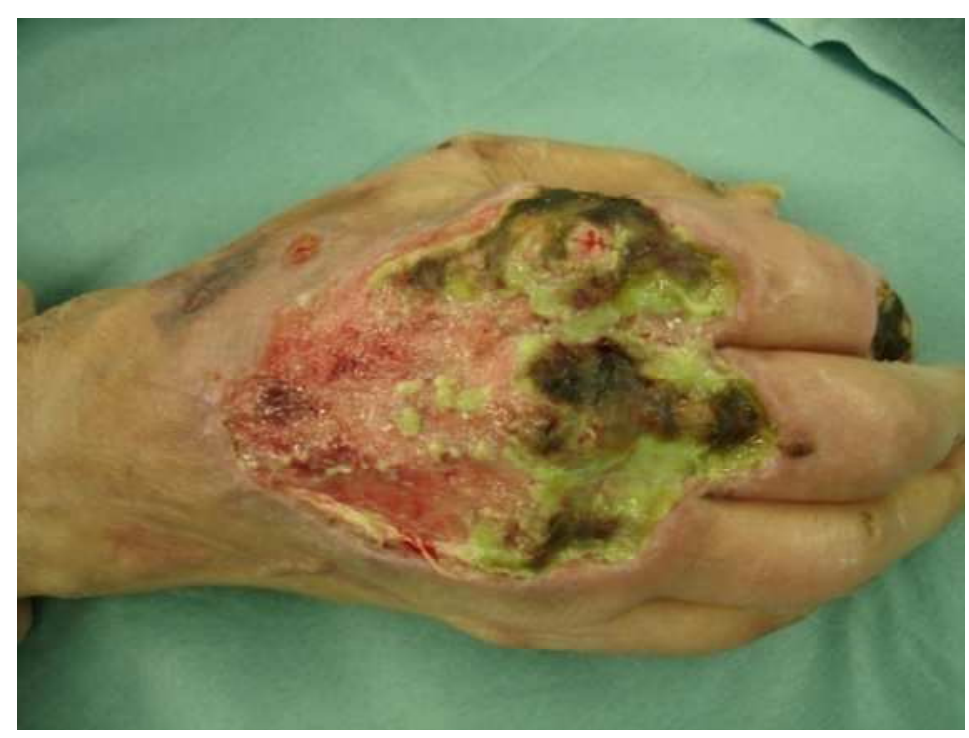

Fig. 1. (A) A 54-year-old woman was referred from an emergency unit for complex necrotic ulcer of the right hand with high fever. She had systemic lupus erythematosus and had been treated with $20 \mathrm{mg} /$ day of prednisolone for 40 years. She had received hemodialysis because of lupus nephritis for 34 years through a blood access shunt in the right elbow, which also showed inflammation. Debridement of the right hand was immediately performed. 


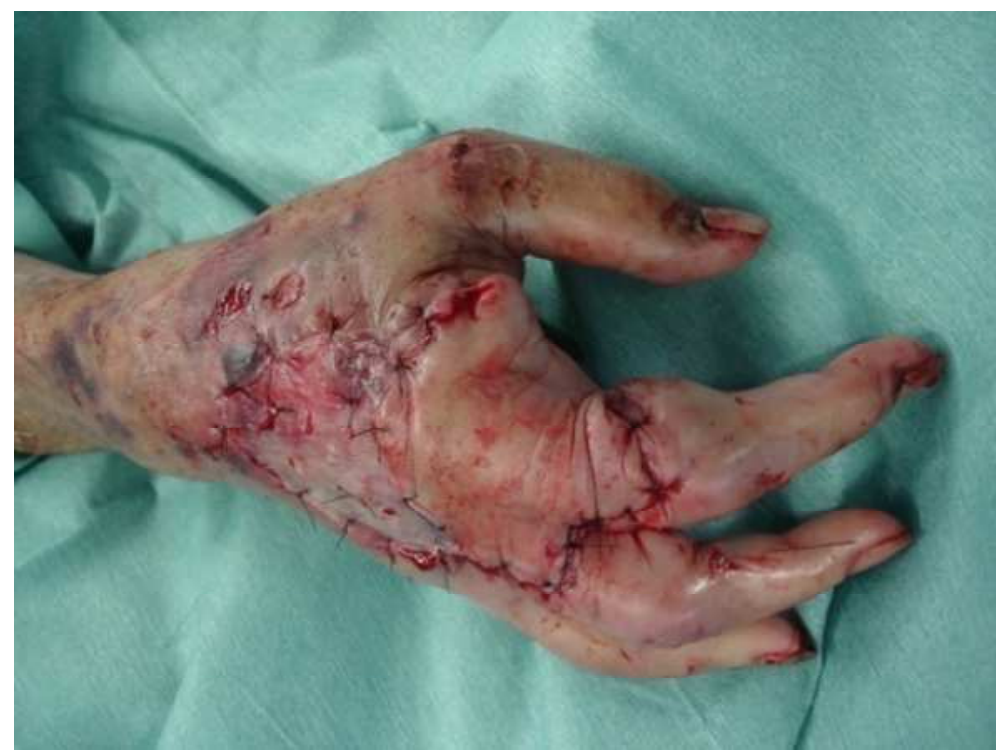

Fig. 1. (B) As the patient's wound improved over a period of 1 month, she underwent resurfacing surgery using local flap transfer and free skin grafting. The wound had completely resurfaced by 2 weeks after surgery.

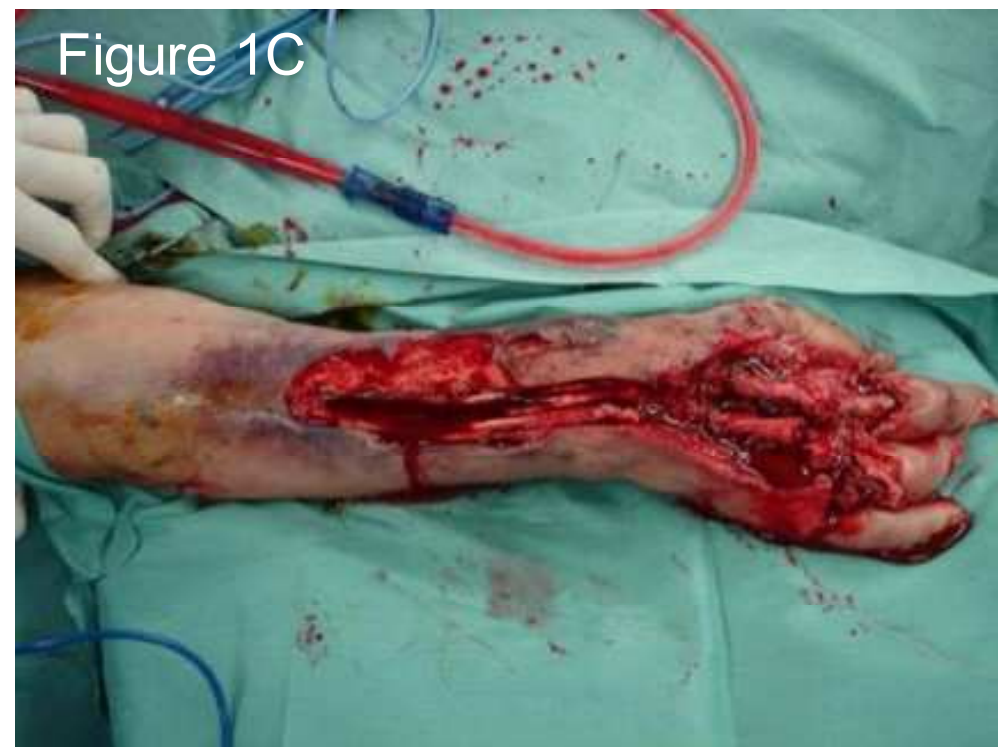

Fig. 1. (C) However, the wound aggravated and marked erythema expanded rapidly to the upper arm over the course of one day, which required immediate amputation of the infected hand at the forearm. 

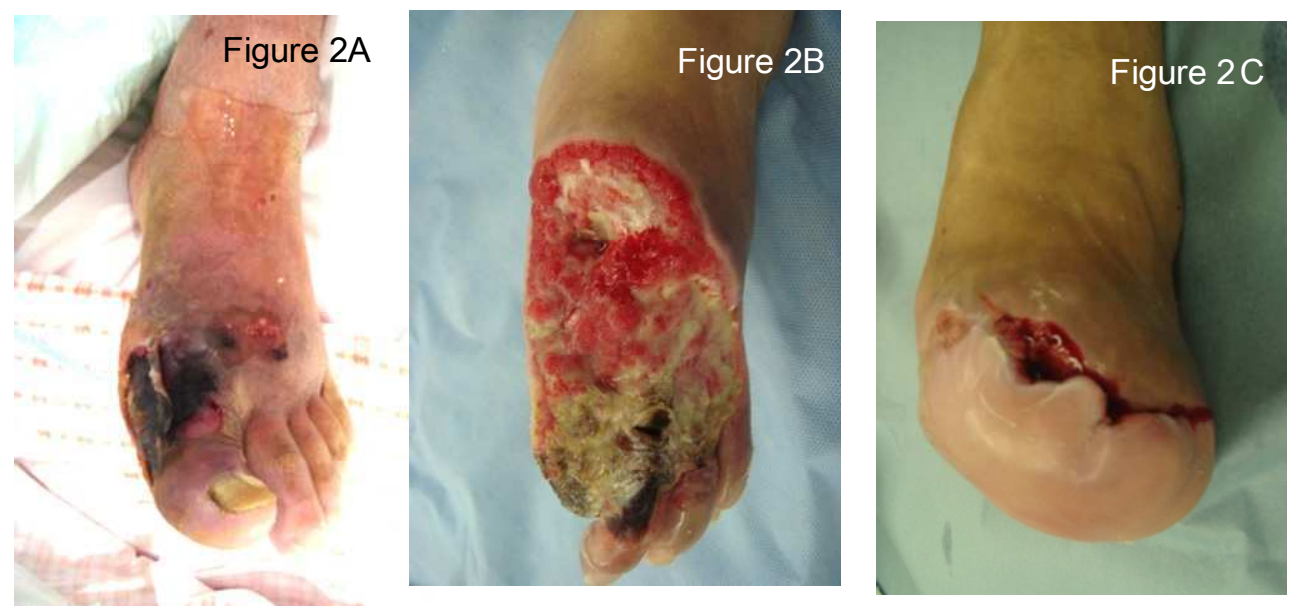

Fig. 2. (A) A 56-year-old man was referred from an emergency unit for a complex necrotic ulcer caused by a burn to the left foot with high fever. He had received hemodialysis because of diabetes mellitus for 4 years through a blood access shunt in the right elbow, which also showed inflammation. Amputation of the left big and $2^{\text {nd }}$ toes was immediately performed. (B) As soft tissue necrosis progressed after debridement, and osteomyelitis occurred 1 month later, he underwent further amputation. (C) The wound improved over a period of 1 month with favorable granulation.

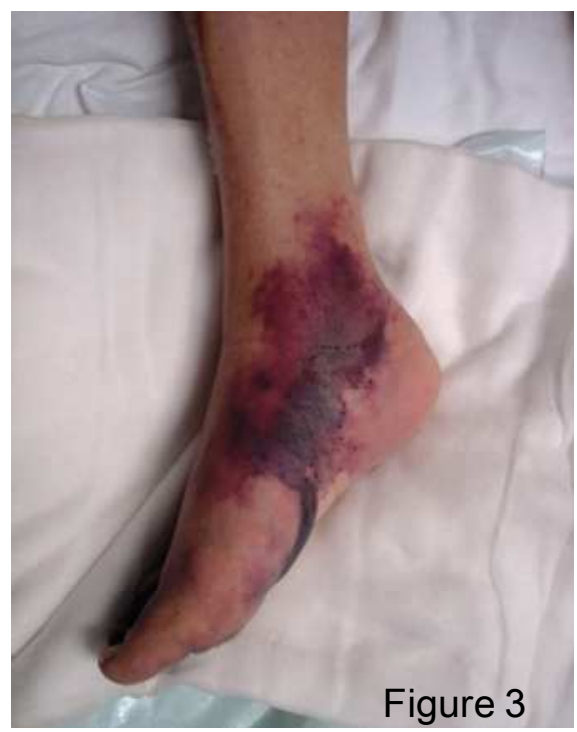

Fig. 3. A 65-year-old man was referred from an emergency unit for severe pain and a complex necrotic ulcer of the bilateral feet. He had arteriosclerosis obliterans, and had received hemodialysis because of chronic glomerulonephritis for 34 years. Right below-knee amputation was performed. 
The number of patients requiring HD because of obesity-related renal diseases such as diabetes mellitus is increasing 5,6 . This article focuses on the prevalence of complex wounds among patients with chronic renal failure (CRF) undergoing hemodialysis, and shows effective and successive treatments of these wounds.

We report our 6-year experience involving 30 patients receiving HD who had chronic skin ulcers. In addition, we investigated the differences in characteristics between patients receiving $\mathrm{HD}$ because of $\mathrm{DM}$ and those receiving HD due to other diseases.

\section{How do complex wounds develop in patients receiving hemodialysis?}

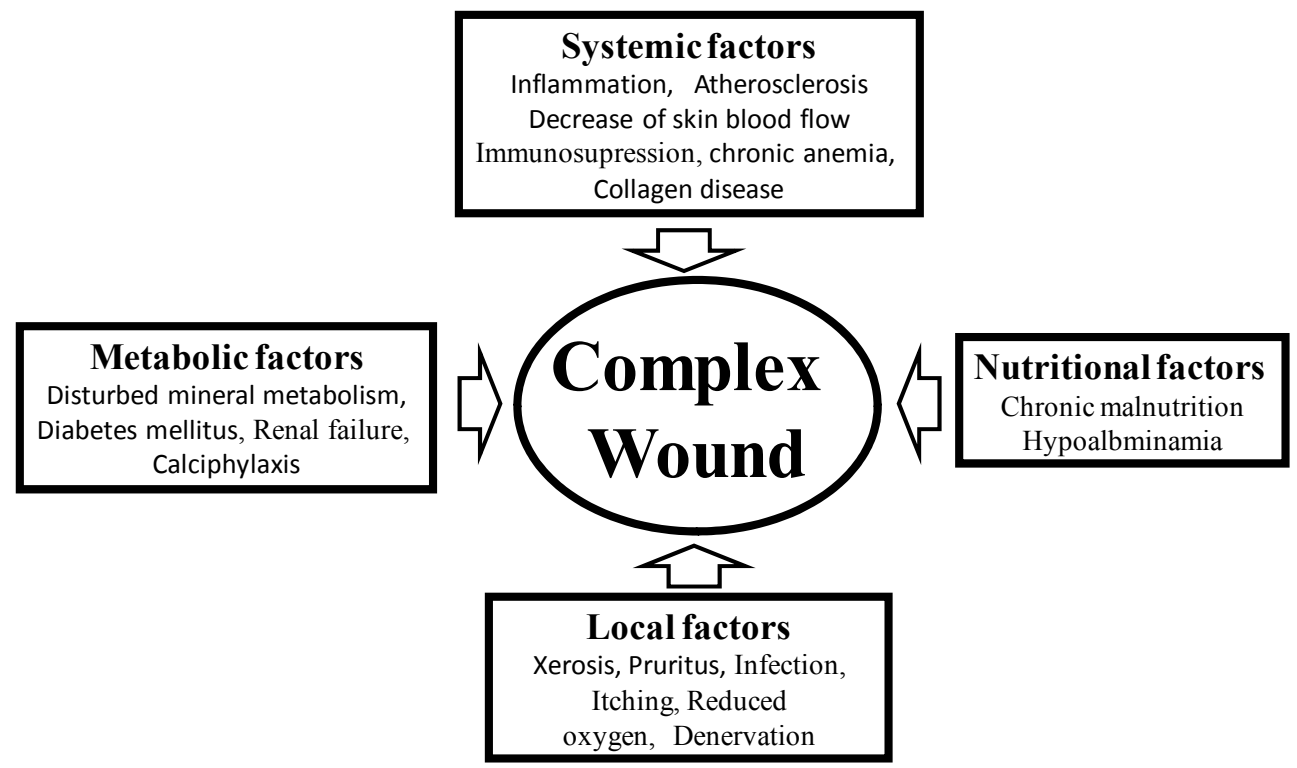

Fig. 4. Factors of complex wound development in patients receiving hemodialysis

Chronic renal failure affects practically all the systems of the body, causing neurological, gastrointestinal, cardiovascular, pulmonary, hematological, endocrine-metabolic, and dermatological disorders 7). Among them, cutaneous disorders are one of the common problems in patients on long-term hemodialysis, which may not be only due to renal dysfunction, but may also be due to complications resulting from treatment. The commonest skin disorders are xerosis and pruritus 8,9). Recent epidemiological studies have demonstrated that the prevalence of pruritus among patients who are adequately dialyzed remains high, ranging between 42 and $75 \%{ }^{10-12)}$. Uremic pruritus is very frustrating for patients since no effective treatment for relief of the itching has been demonstrated. The pathophysiological mechanisms of pruritus are mainly unknown, despite several hypotheses being presented 13).

Furthermore, the skin of patients on hemodialysis is dry, and so the skin barrier structure and function are impaired 14). The Observational Dialysis Outcomes and Practise Patterns 
Study, collecting data from more than 29,000 HD patients, showed that $42 \%$ of HD patients experience moderate to extreme itching ${ }^{15}$ ). The impaired skin resistance and stimuli caused by scrunching because of itchy skin cause continuous inflammations, which contribute to local skin ulcers and the general development of malnutrition and cardiovascular disease 16). In addition, disturbed mineral metabolism is associated with skin complaints in dialysis patients 17$)$. Other cutaneous manifestations include scaling (9.9\%), pressure ulcer (2.0\%), and dermatitis $(2 \%){ }^{18,19)}$.

Regarding cutaneous infection, Bencini et al. reported that the incidence of fungal infection in patients undergoing hemodialysis was $67 \%$ 20). CRF patients exhibit impaired cellular immunity due to a decreased T-lymphocyte cell count; this could explain the increased prevalence of fungal infections ${ }^{21}$. Other cutaneous infections include bacterial $(13 \%)$ and viral $(12 \%)$ infections, reportedly common in diabetics ${ }^{9}$ ). Difficulty healing wounds is a frequent problem in patients on HD because of their poor general conditions, including malnutrition, inflammation, and atherosclerosis syndrome 1). Stein and Wiersum, in a retrospective analysis of 22,389 laparotomies, concluded that dysfunction played a significant role in the development and outcome of abdominal wound dehiscence 2). Not only abdominal surgical wounds, but also all surgical sites sometimes develop poor wound adhesion causing a complex ulcer (Figure 5). Mistrík et al. reported at significant decrease in skin blood flow during the HD procedure and concluded that the skin blood flow may be impaired in HD patients, which leads to the development of difficulty in healing skin wounds ${ }^{3}$ ). Consequently, patients with end-stage renal disease were associated with higher resource use, complication rates, and mortality when they were injured 22).

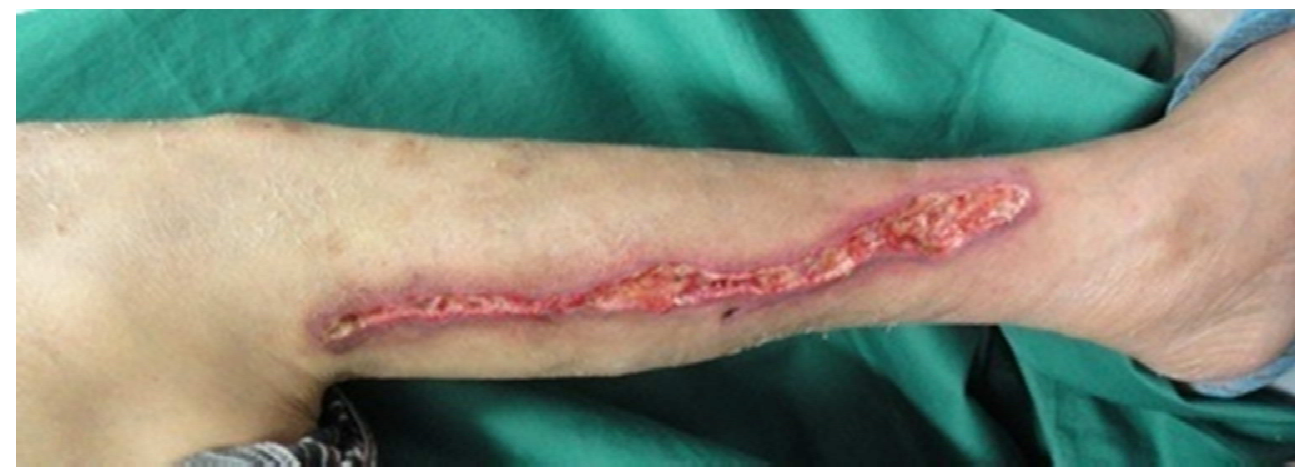

Fig. 5. Development of a complex leg ulcer because of wound dehiscence, following great saphenous vein harvest for vein grafting.

\section{Profiles and clinical status of HD-receiving patients who develop extremity ulcers because of diabetes mellitus or other diseases}

Thirty patients receiving HD who had chronic wounds of the limbs underwent surgical treatment in our unit from 2004 through 2010. The ages ranged from 52 to 89 years (mean, 66.5 years). 


\subsection{Causative disease in patients receiving HD}

Patients receiving HD because of DM (57\%) ranged in age from 53 to 74 years (mean, 62.4 \pm 7.9 years), and patients receiving HD because of other diseases, including chronic glomerular nephritis (CGN), polycystic kidney, and systemic lupus erythematosus (43\%), ranged in age from 52 to 69 years (mean, $61.3 \pm 6.0$ years) (no significant difference, Wilcoxon rank sum test). All diabetic patients were classified with type 2 diabetes mellitus. Serous calcium level of diabetic patients ranged from 7.1 to $9.3 \mathrm{mg} / \mathrm{dl}$ (mean, 8.5 $\pm 0.7 \mathrm{mg} / \mathrm{dl}$ ), and that of non-diabetic patients ranged from 8.9 to $10.2 \mathrm{mg} / \mathrm{dl}$ (mean, $9.6 \pm$ $0.5 \mathrm{mg} / \mathrm{dl}$ ). There was no significant difference between the groups ( $\mathrm{p}=0.5$, Wilcoxon rank sum test). Inorganic phosphate levels of diabetic patients ranged from 2.4 to $4.2 \mathrm{mg} / \mathrm{dl}$ (mean, $3.7 \pm 0.6 \mathrm{mg} / \mathrm{dl}$ ), and that of non-diabetic patients ranged from 2.8 to $4.6 \mathrm{mg} / \mathrm{dl}$ (mean, $3.2 \pm 0.8 \mathrm{mg} / \mathrm{dl})$. There was no significant difference between the groups $(\mathrm{p}=0.4$, Wilcoxon rank sum test).

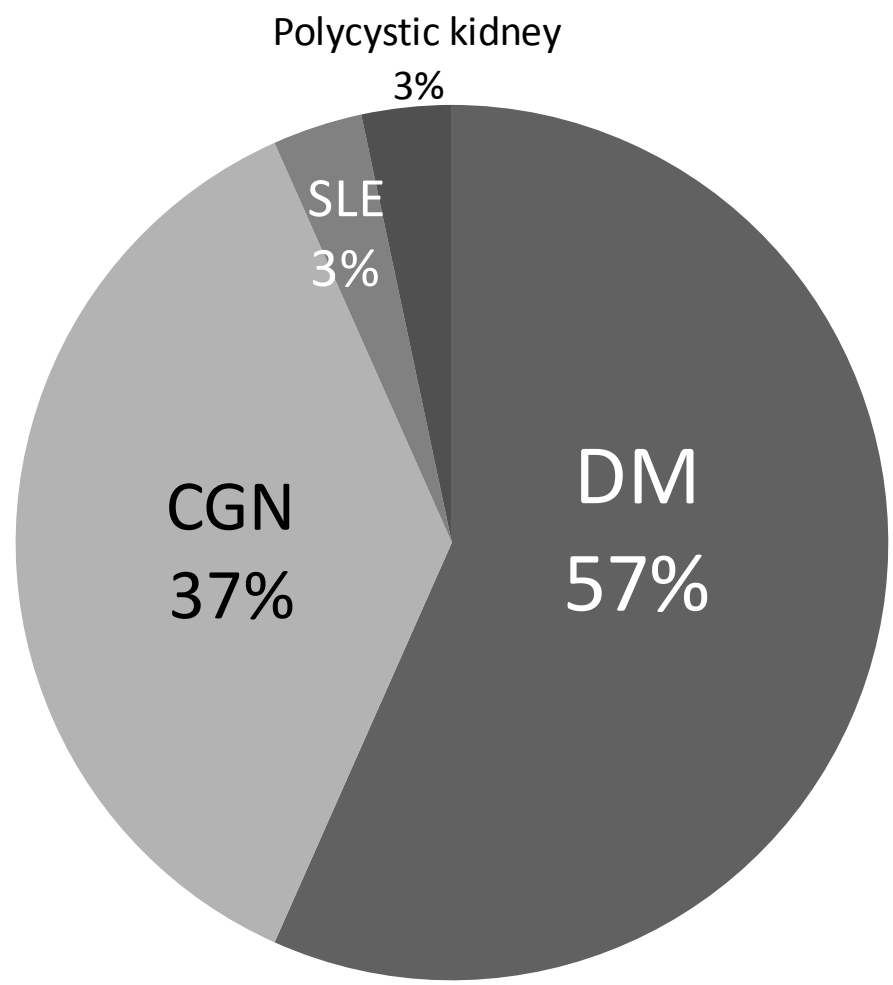

Fig. 6. Causative disease in patients receiving $\operatorname{HD}(\mathrm{N}=30)$

We investigated differences in the cause of wounds, size of wounds, need for immediate debridement, and interval between the start of HD and wound development, between patients with chronic renal failure due to DM and that due to other diseases (Tables 1, 2). All information was obtained from patients' medical records, examinations, and an interview at the first examination. 


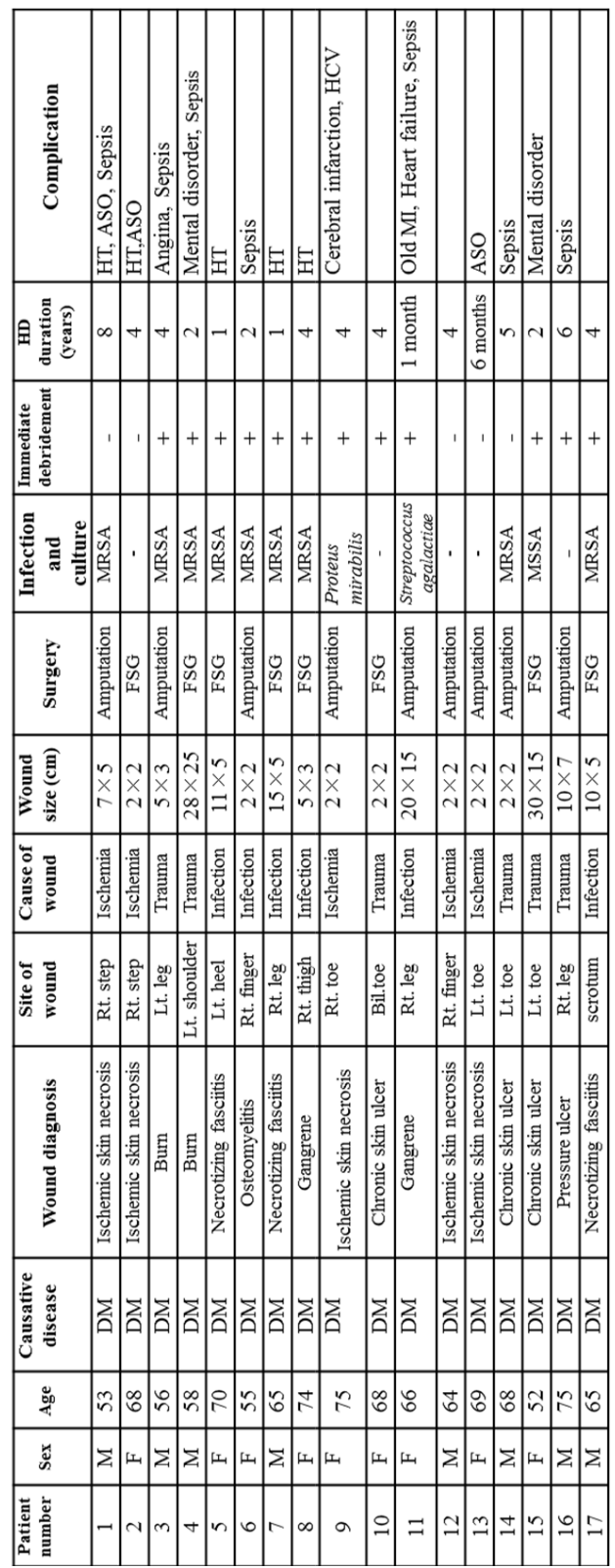

DM, diabetes mellitus. CGN, chronic glomerulonephritis. FSG, free skin grafting. SLE, systemic lupus erythematosus. MRSA, methicillin-resistant Staphylococcus aureus. HT, hypertension. ASO, arteriosclerosis obliterans

Table 1. Profiles and clinical status of patients undergoing HD with extremity ulcers due to diabetes mellitus. 


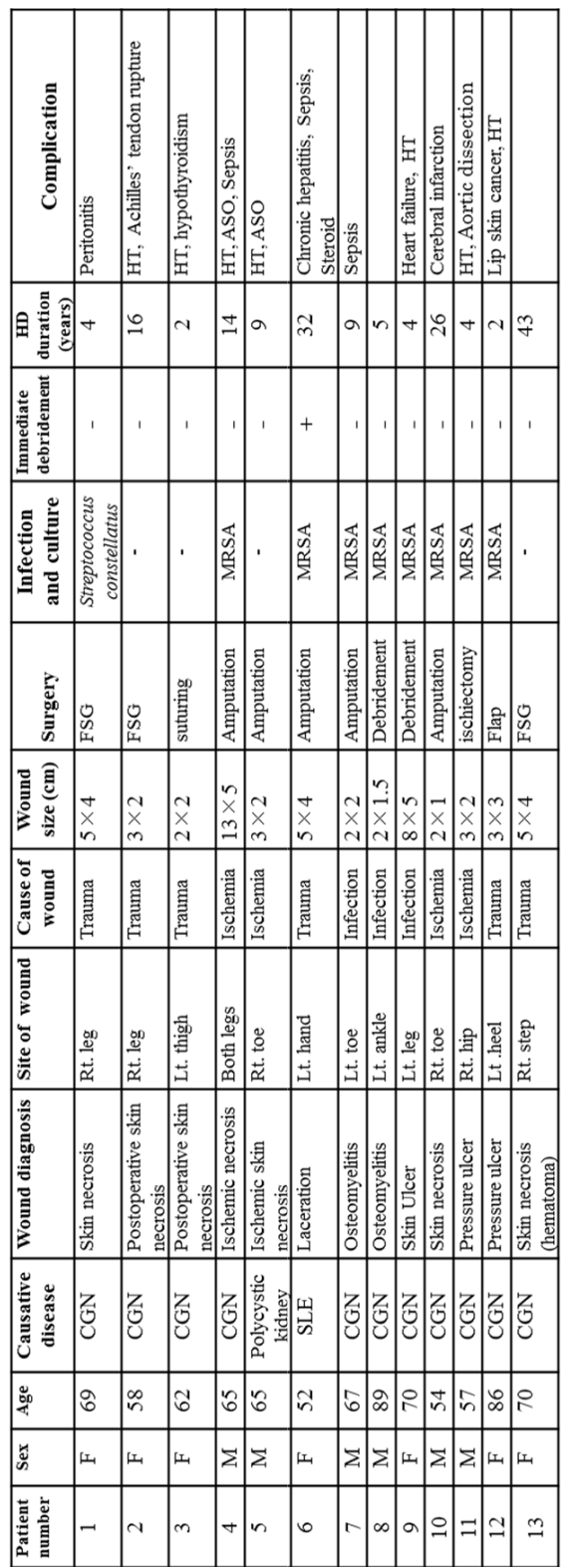

DM, diabetes mellitus. CGN, chronic glomerulonephritis. FSG, free skin grafting. SLE, systemic lupus erythematosus.

MRSA, methicillin-resistant Staphylococcusa complex HT, hypertension. ASO, arteriosclerosis obliterans

Table 2. Profiles and clinical status of patients undergoing HD with extremity ulcers due to diseases other than diabetes mellitus. 


\subsection{Cause of wounds in patients with CRF due to DM or other diseases}

Wounds in patients with CRF due to DM were caused by trauma (burns and pressure ulcers) in 6 cases $(35.3 \%)$, infection in 6 cases $(35.3 \%)$, and ischemia in 5 cases $(29.4 \%)$. Wounds in patients with CRF due to other diseases were associated with trauma in 6 cases $(46.5 \%)$, infection in 3 cases $(23.2 \%)$, and ischemia in 4 cases (30.3\%) (Figure 7).

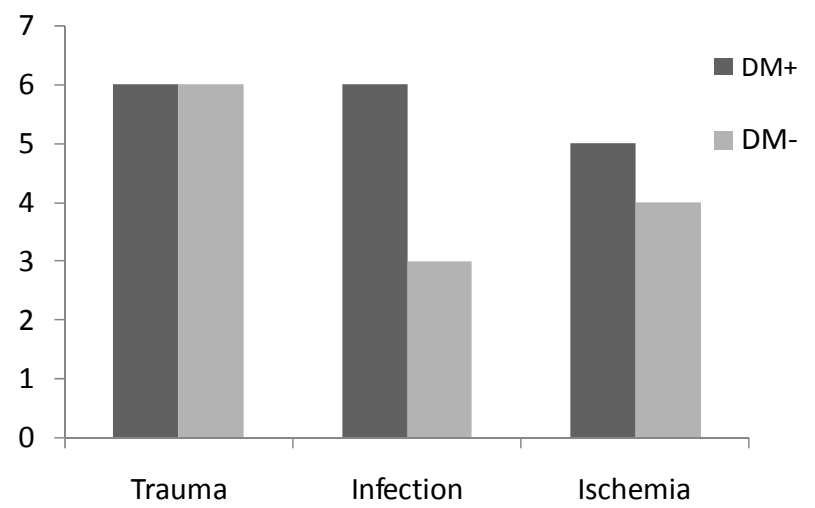

Fig. 7. Cause of wounds in patients with CRF due to DM or other diseases.

\subsection{Differences in wound size in CRF caused by DM and other diseases}

The size of wounds in patients with DM ranged in area from 4 to $450 \mathrm{~cm}^{2}$ (mean, $69.5 \pm 120.8$ $\mathrm{cm}^{2}$ ), and that in patients without DM ranged from 3 to $65 \mathrm{~cm}^{2}$ (mean, $617.8 \pm 18.9 \mathrm{~cm}^{2}$ ) (no significant difference, Wilcoxon rank sum test) (Figure 8).

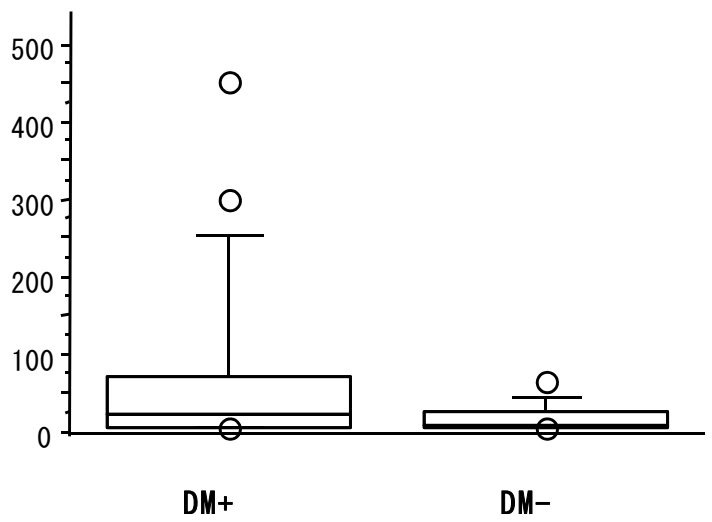

Fig. 8. Differences in size of wounds in CRF due to DM and other diseases.

\subsection{Bacterial infection in patients receiving HD}

Wound infection is common and difficult to control, because cutaneous surfaces are without protective barriers, through which patients receiving HD may easily acquire bacterial infection. Our study revealed that bacilli were cultured from 12 of 17 (70.6\%) wounds in patients with DM. and 9 of $13(69.2 \%)$ without DM. There was no significant difference in the frequency of bacterial isolation between the two groups (chi-square test). Concerning to 
the seriousness of infection, 13 of 17 wounds required immediate surgery including amputation and debridement in patients with DM, while, only 1 of 13 required immediate surgery in patients without DM. There was a significant difference between the groups $(p<0.05$, Chi-square test) (Figure 9). These results suggest that patients receiving HD because of diabetes are likely to develop more severe wound infections.

Methicillin-resistant Staphylococcus aureus (MRAS) was commonly isolated from these contaminated wounds, being isolated from 9 of $12(75.0 \%)$ in the DM group, and 8 of 9 $(88.9 \%)$ in the non-DM group.

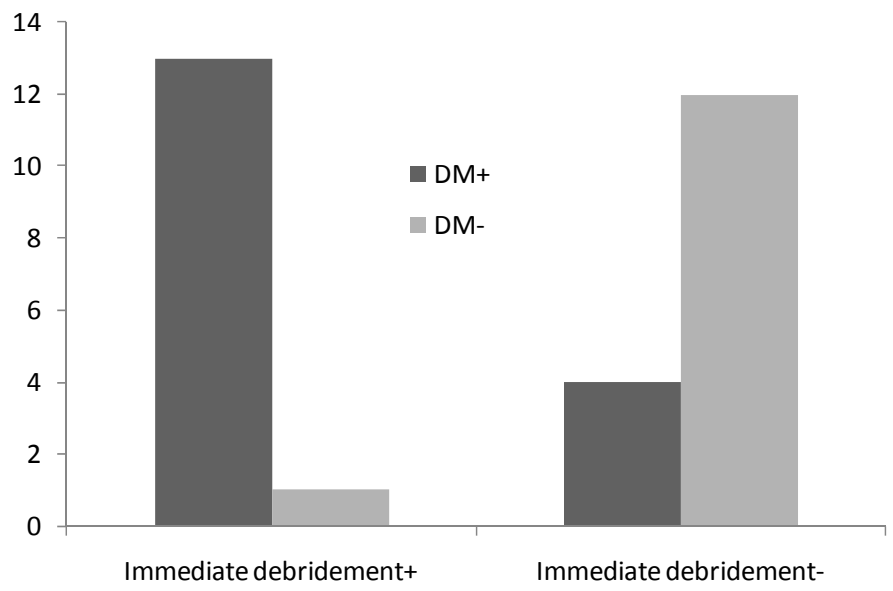

Fig. 9. Need of immediate debridement in patients with CRF due to DM or other diseases.

\subsection{Interval between the start of HD and wound development}

The interval between the start of HD and wound development in patients with DM ranged from 1 month to 8 years (mean, $3.2 \pm 2.1$ years), and that in patients without DM ranged from 2 to 43 years (mean, $12.4 \pm 12.7$ years). It was significantly shorter in patients with than in those without diabetes. ( $p=0.017$, Wilcoxon rank sum test) (Figure 10).

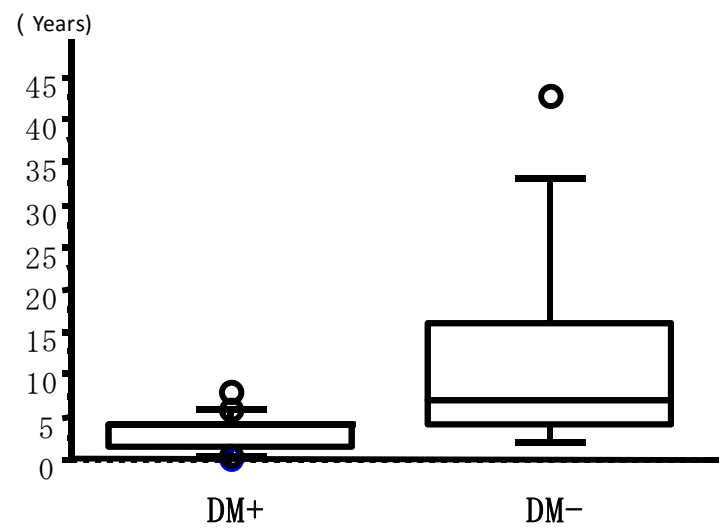

Fig. 10. Differences in the interval between the start of HD and wound development in CRF due to DM and other diseases. 


\section{Treatments of complex wounds in patients receiving HD}

\subsection{Immediate debridement and amputation aiming at infection control}

Extremity ulcers in patients receiving HD are often difficult to heal. Nonetheless, patients with severely ischemic limbs due to maintenance HD are markedly increasing in number 1,2). They often require multiple surgeries because arteriosclerosis obliterans usually progresses, which causes other ischemic ulcers (Figures 2, 11, 12).
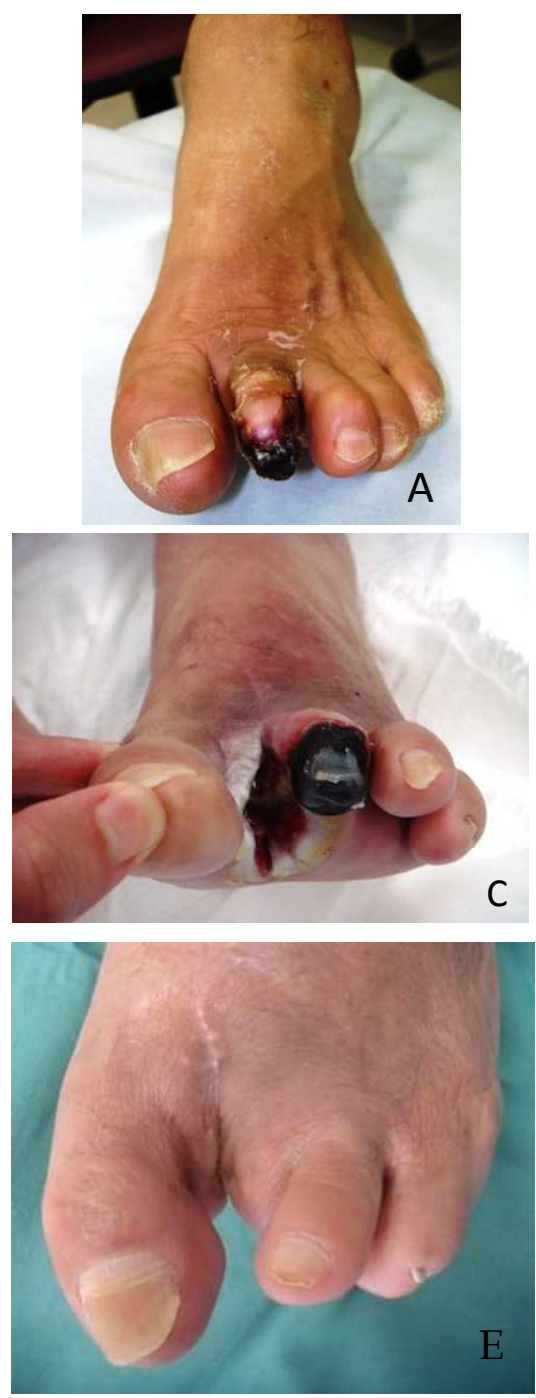
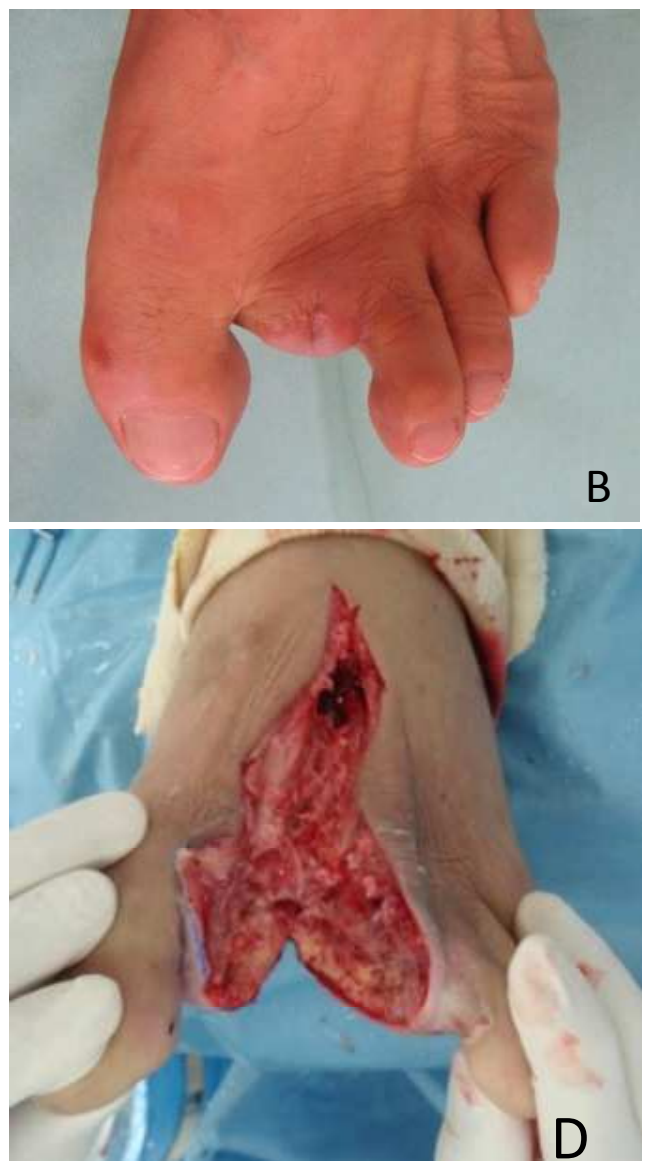

Fig. 11. (A) A patient with an ischemic foot due to maintenance HD developed necrosis of the left $2^{\text {nd }}$ toe. (B) The ulcer was resolved by amputation. (C) However, he developed another site of necrosis with infection (arrow) on the third toe. (D) The patient underwent immediate debridement and osteotomy. (E)The wounds healed satisfactorily. 

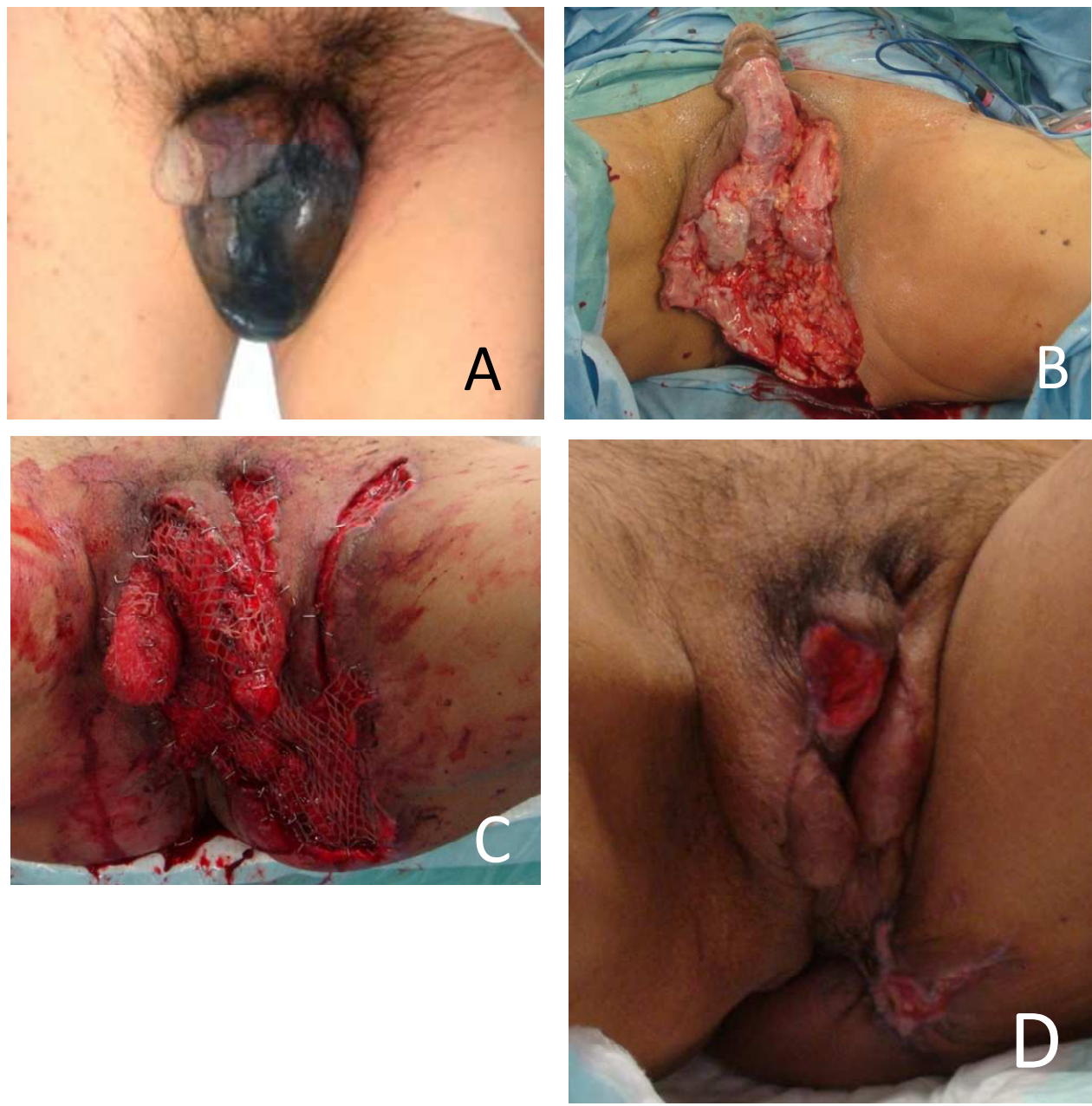

Fig. 12. (A) A case of Fournier's gangrene. A patient receiving HD due to DM developed progressive infection and necrosis of the scrotum and penis. (B) He underwent immediate debridement. (C)The wound was resurfaced with a mesh graft 2 weeks later. (D) However, necrosis of the penis progressed, and so the patient underwent amputation of the penis

Amputations of limbs or fingers are sometimes performed for these complex ulcers, because patients receiving HD are thought to present with immunocompromised conditions, and aggressive life-threatening infections such as sepsis require immediate surgical debridement in order to salvage the blood access line and their life (Figure 13). Only administrating antibiotics for the contaminated wound containing necrotic tissue is of no use and worsens the condition of patients, because antibiotic agents cannot reach the non-vascularized and infected necrotic mass. Immediate surgical debridement is the only recommended way to resolve these soft tissue infections (Figure 14) 23, 24). Surgical amputation is sometimes the only way to resurface these wounds, especially for some ischemic necrotic wounds including total finger or foot dry 
necrosis. In our study, 14 patients underwent finger or limb amputation, with 9 due to complicated sepsis and 5 due to dry necrosis associated with arteriosclerosis obliterans.
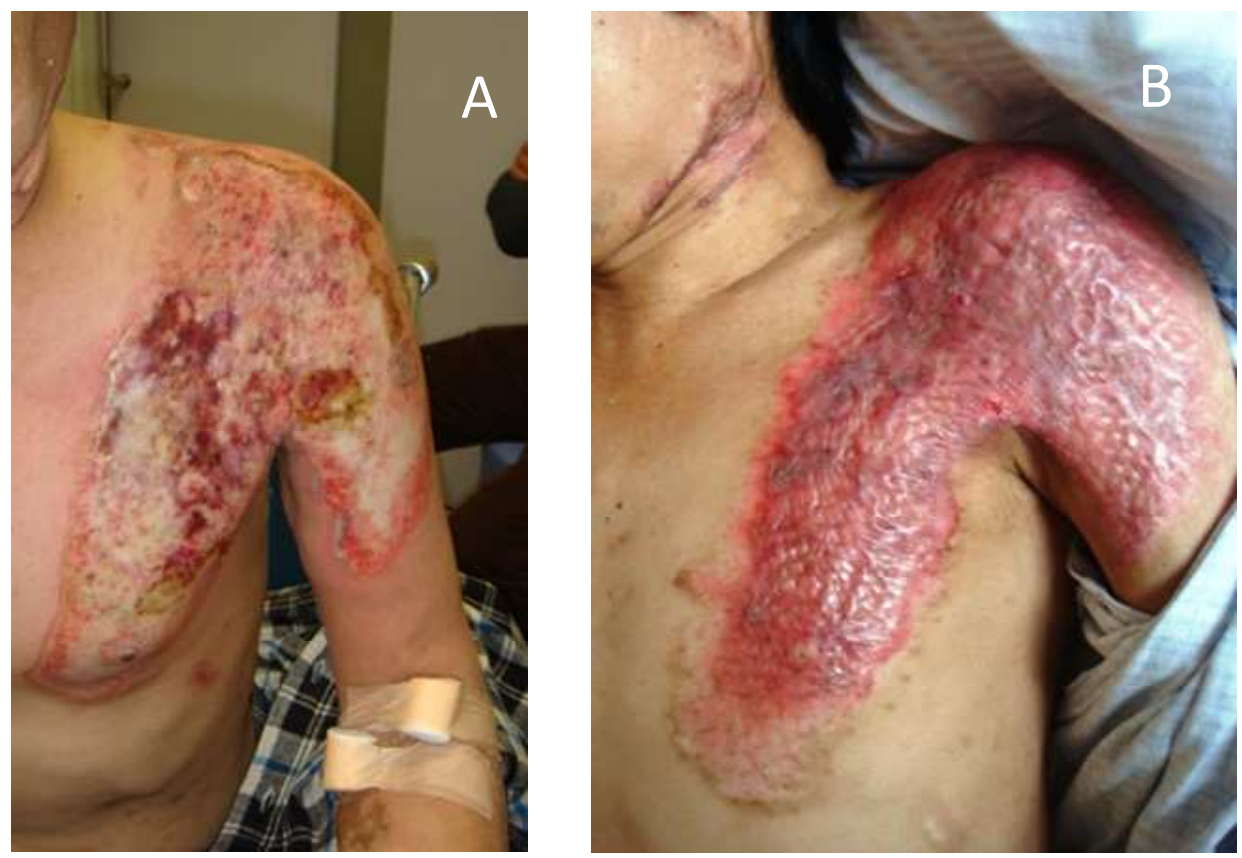

Fig. 13. (A) A 63-year-old man who suffered a burn visited our medical center 4 days after injury. He had received hemodialysis because of diabetes mellitus for 2 years. The blood access shunt in the left elbow, shown in the picture. On the first examination, the burn wound was covered with necrotic eschar with infection, and the patient showed burn wound sepsis with high fever. Debridement and free skin grafting were immediately performed. (B) The burn wound had resurfaced 3 weeks after surgery.

It is commonly believed that the development of ischemic limb ulcers in patients with CRF is influenced by underlying advanced diabetic microangiopathy ${ }^{25)}$. Although we have investigated severe extremity ulcers requiring surgical treatment, the present study indicates that the development of ulcers in patients with DM is not only associated with ischemia but is also strongly influenced by infection, because 11 of 13 patients with DM had infectious conditions such as gangrene, osteomyelitis, necrotizing fasciitis, and/ or sepsis. On the other hand, the development of ulcers in patients without DM was mainly due to ischemia and trauma. Only 2 patients developed MRSA sepsis originating from secondary wound infection, and they underwent amputation.

The interval from the start of HD to wound development in patients with was significantly shorter than that in those without DM. Generally, ulcers in patients with CRF and DM are thought to develop because of peripheral neuropathy, which reduces protective sensations 26). In addition, several investigators have reported incidences of peripheral arterial occlusive disease in patients receiving HD ranging from 2.5 to $19.0 \% 27,28$ ). Because of these neurovascular disorders, extremity ulcers develop more easily in patients with DM than in those with other diseases. 
These infectious wounds often result in higher mortality rates because blood access shunts, especially when an artificial vessel is grafted, are easily infected. Bacteria from the wounds usually diffuse proximally along the subcutaneous flow of lymph or blood and can cause shunt infections, which lead to the loss of blood access channels and life-threatening sepsis. All our patients with infectious wounds (14 cases) required immediate debridement, including amputation to prevent such unfavorable general infections, because aggressive local inflammatory reactions had already developed (Figure 14). Thirteen of these patients had DM.
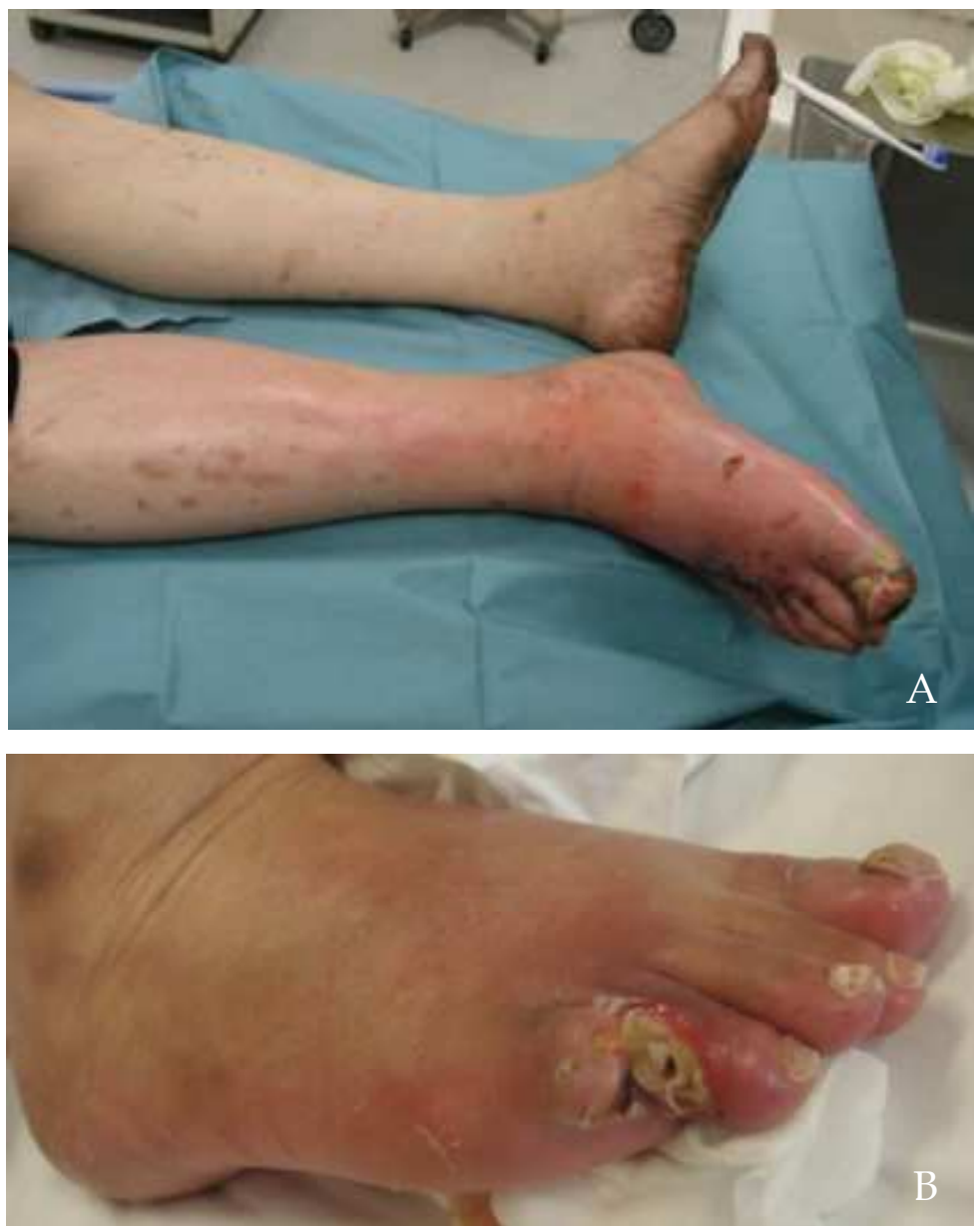

Fig. 14. (A) A 65-year-old man developed necrotizing fasciitis of the right leg, with pain and high fever. He had received hemodialysis because of diabetes mellitus for 1 year. The blood access shunt in the right elbow showed inflammation. Below-knee amputation was immediately performed. (B) A 52-year-old man developed a complex necrotic ulcer on the right foot with a high fever. He had received hemodialysis because of diabetes mellitus for 2 years. His blood access shunt in the left elbow also showed inflammation. Amputation of the fifth toe was immediately performed. 
MRSA was isolated from almost all chronic wounds in patients with DM, which also suggested that HD-receiving patients with DM tend to bear multi-drug-resistant organisms, and, thus, strict infection control is required to prevent outbreaks.

The control of infection after aggressive debridement is the most important point to heal the wound and prevent the recurrence of infection. When initial debridement is insufficient and local infection recurs, further debridement is required. Wound infection cannot be controlled in the presence of necrotic tissue. If a patient shows relapsed wound infection without necrosis and foreign bodies remaining in the wound, cleansing the wound using continuous irrigation employing suction and irrigation system is recommended. This was also adapted for the treatment of osteomyelitis (Figure 15) ${ }^{29}$ ). It is concluded that when a risk of recurring an infection remains after primary debridement, two-stage management, involving late second stage surgery included secondary debridement and stable reconstruction, should be considered. ${ }^{30}$ )
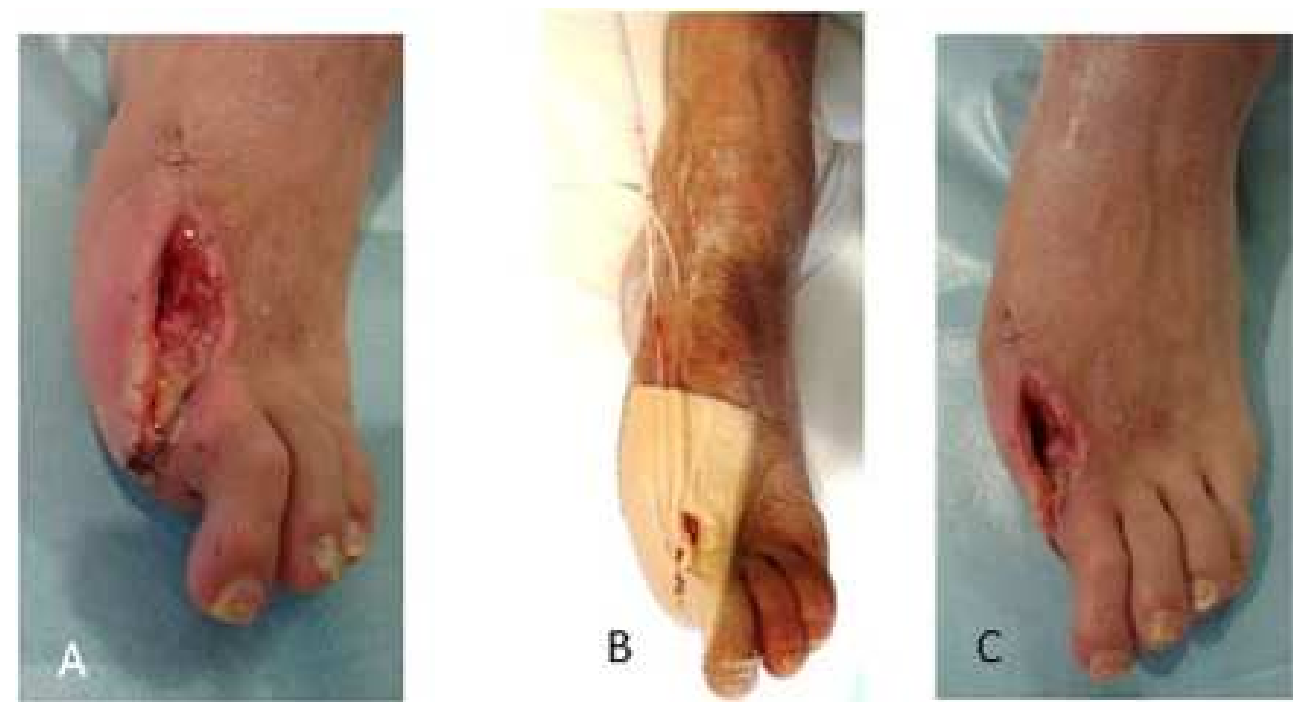

Fig. 15. (A) A patient receiving HD because of DM for 3 years developed osteomyelitis of the left big toe, and underwent debridement and wound closure. However, the soft tissue infection relapsed 5 days later. (B) He underwent secondary debridement and continuous irrigation, using a suction and irrigation system. (C) Three weeks later, the wound was covered with abundant granulation tissue with no infection. The wound closed spontaneously.

\section{Wound bed preparation for patients receiving HD}

After the debridement of necrotic tissue, the wound bed needs to be prepared to receive either a graft or flap. ${ }^{31}$ ) The resurfacing of wounds is one of the most important procedures, because such wounds will cause further infection, exudates, odors, and bleeding, which decrease the patient's quality of life. Chronic ulcers may sometimes prevent the patient from living at home. ${ }^{32)}$ Wound bed preparation has allowed uncomplicated wounds to heal quickly. ${ }^{23,33-37)}$ The management of chronic wounds has progressed from assessing the 
status of a wound to understanding the underlying molecular and cellular abnormalities that prevent the wound from healing. The concept of wound bed preparation offers a systematic approach to remove barriers to healing such as tissue (non-viable), infection/inflammation, moisture (imbalance), and edge (non-advancing or undermining) and enhancing the effects of advanced therapies. ${ }^{35,36)}$ Wound bed preparation is an essential element of wound management that advances endogenous healing as well as the efficacy of topical and other wound therapy.38) Wound bed preparation techniques will allow complex wounds to grow abundant granulation tissue. When a wound is covered with suitable granulation and no contamination is observed, free skin grafting should be performed as soon as possible (Figure 16). In cases of bone- or tendon-exposed wounds, some flaps are required to resurface the wounds, because grafted skin will not take directly on tendon or bone (Figure 17).
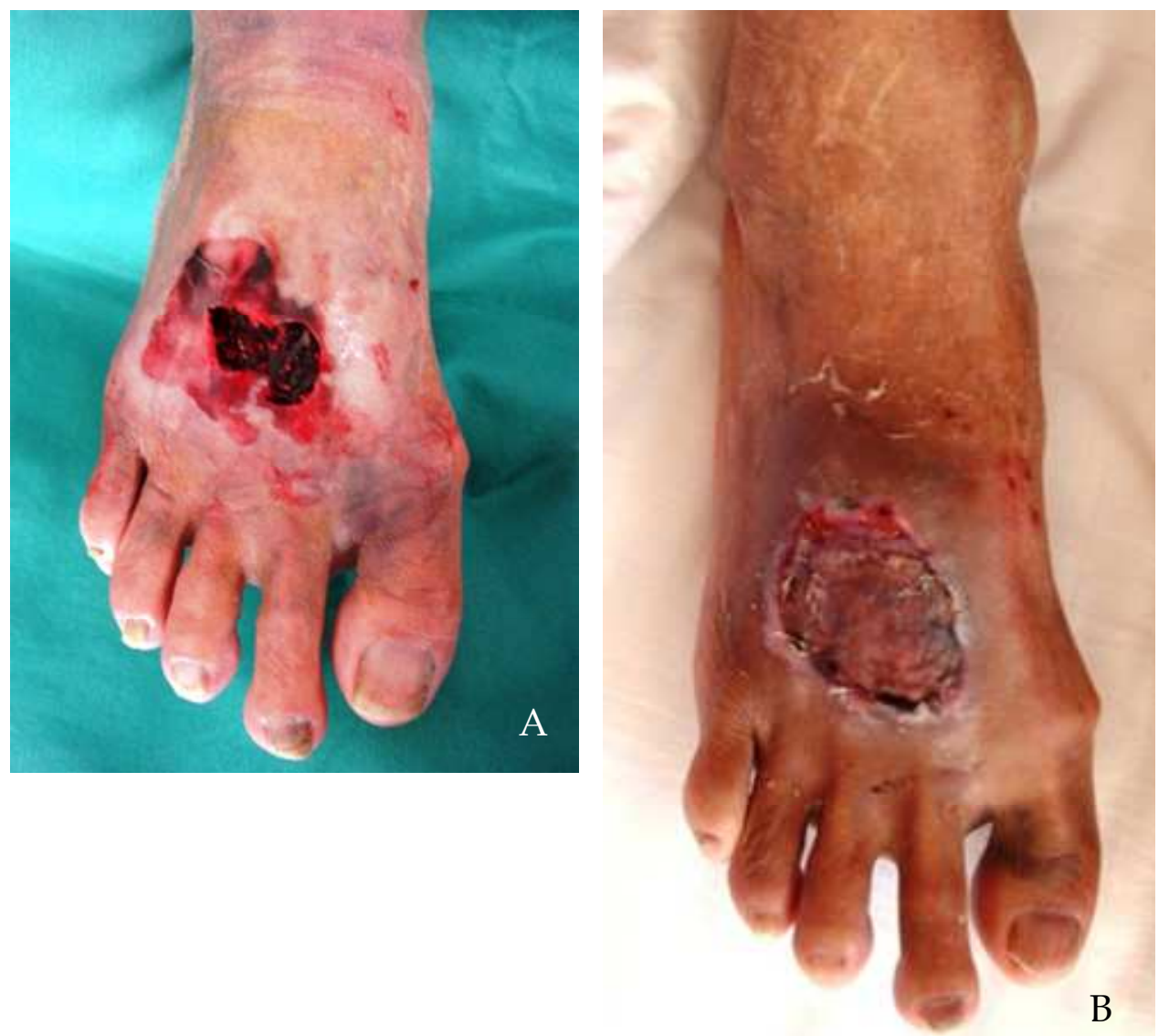

Fig. 16. (A) A 86-year-old female suffered a hematoma due to falling on a step. She had received hemodialysis because of chronic glomerulonephritis for 43 years. (B) Three weeks after the treatment of the wound bed, abundant granulation tissue was observed. She underwent a free skin graft, and the wound resurfaced favorably. 

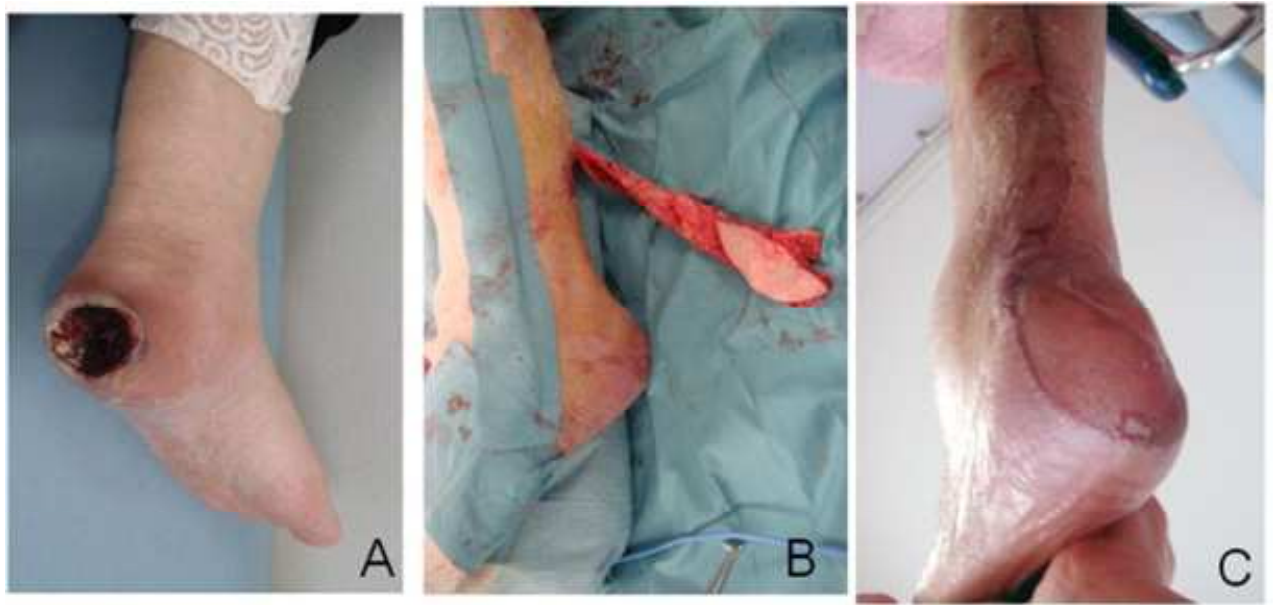

Fig. 17. (A) An 86-year-old female suffered from a bone-exposed wound due to a pressure ulcer on the heel. She had received hemodialysis because of chronic glomerulonephritis for 2 years. (B) She underwent reversed sural flap surgery. (C) The wound was completely resurfaced. She regained the ability to walk.

\section{Several adjuvant and devices in the management of hard-to-heal wounds}

In this section, several adjuvant and devices are presented, including growth factor, bioengineered tissues, and a negative pressure system, which are combined for the improved clinical treatment of complex wounds. ${ }^{24)}$

Firstly, several growth factors have been used clinically to prepare favorable wound beds. Of these growth factors, basic fibroblast growth factor (bFGF) is the only angiogenic cytokine currently available in Japan. ${ }^{39)}$ Treatment with bFGF allows chronic ulcers to heal more quickly (Figure 18). ${ }^{40)}$ Secondly, artificial dermis, which is composed of atelocollagen sponge and a silicone membrane, is beneficial for these wounds because of its unique characteristics (Figure 19). Atelocollagen sponge allows the early infiltration of mononuclear cells and fibroblasts, leading to the rapid resolution of inflammatory reactions and more favorable growth of granulation tissue. On the other hand, the silicone membrane protects against a loss of fluid, protein, and electrolytes, which helps maintain a suitable environment for wound healing. 41, 42) Formerly, resurfacing tendon- or bone-exposed wounds required vascularized flaps, showing high morbidity at the donor site, skilful micro- or plastic surgeons, microsurgical instruments, and much time, because a free skin graft would not take on unfavorable wound beds, such as in the presence of infected granulation and low-vascular tissues. ${ }^{41)}$ Artificial dermis is beneficial for the reconstruction of these wounds because it promotes the early infiltration of mononuclear cells and fibroblasts and better growth of connective tissue strands and epithelium. ${ }^{41-43)}$ 

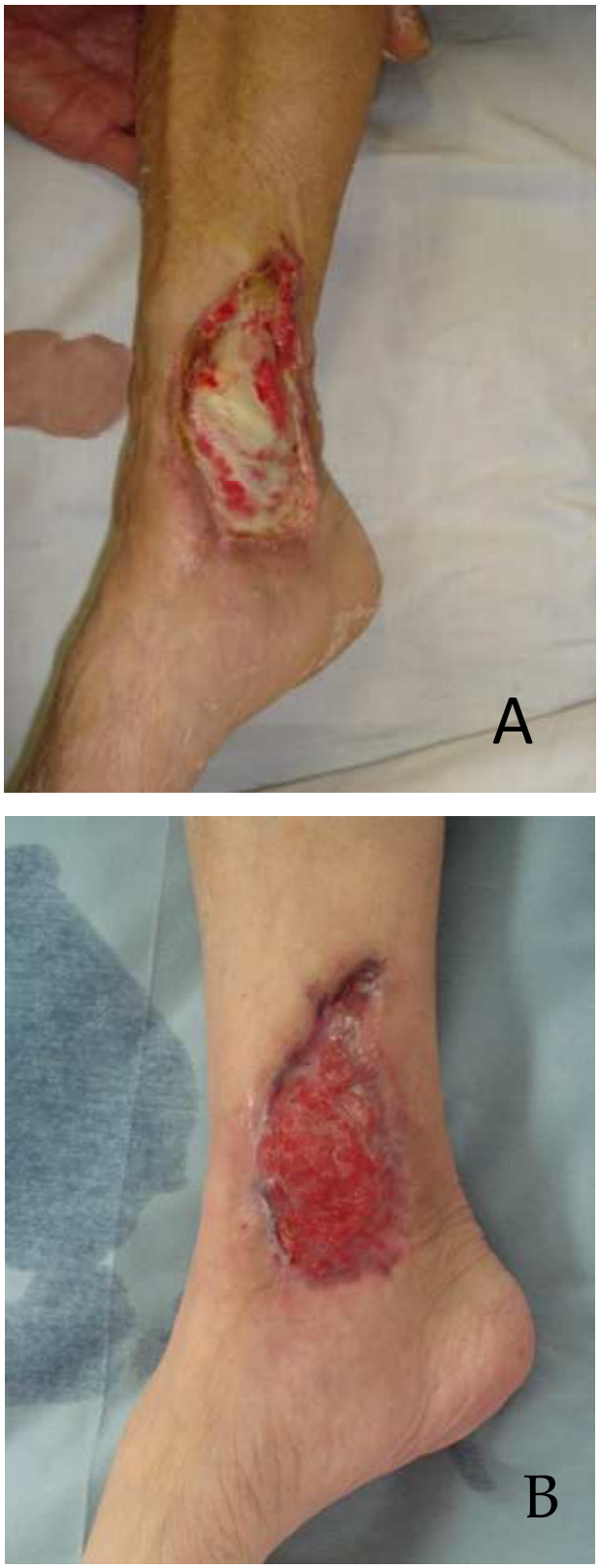

Fig. 18. (A) A 63-year-old female suffered from a tendon-exposed wound due to instillation into the subcutaneous tissue of the ankle. She had received hemodialysis because of chronic glomerulonephritis for 4 years. (B) Three weeks after wound bed preparation with basic fibroblast growth factor. Abundant granulation tissue suitable for free skin grafting was observed. The wound completely resurfaced after skin grafting. 
Silicone membrane

$\downarrow$

\section{Collagen sponge}
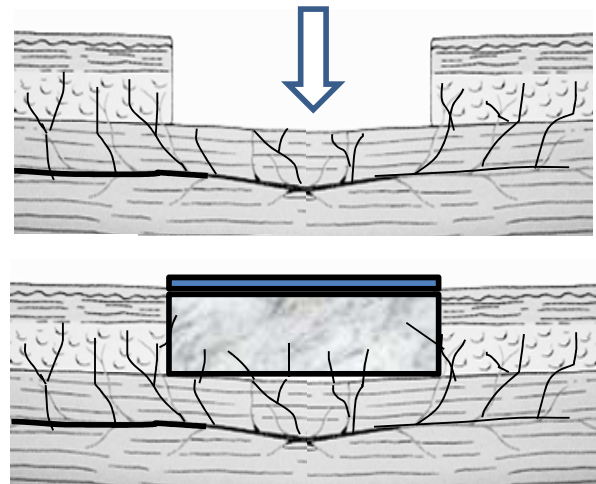

Fibroblasts and capillaries infiltrate into the collagen sponge
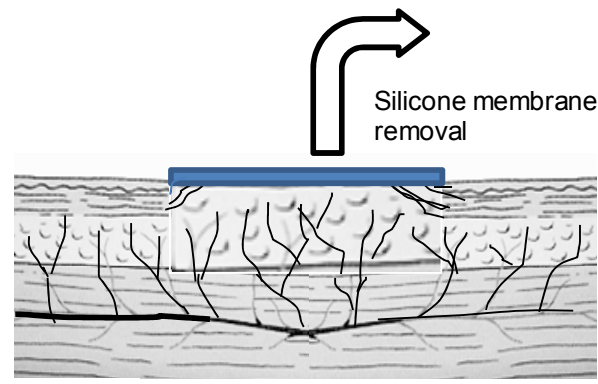

Collagen sponge is absorbed, and abundant granulation tissue develops over the wound

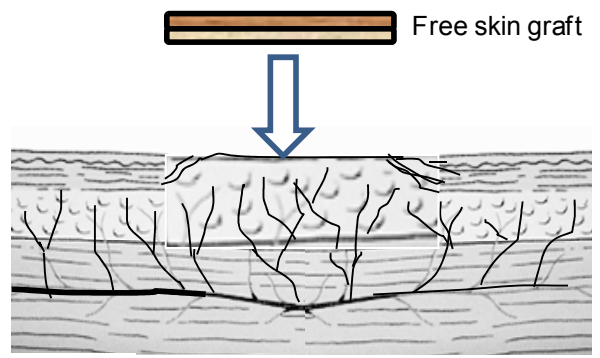

Free skin grafting is performed over the prepared suitable wound bed

Fig. 19. Treatment of a full-thickness skin defect ulcer using artificial dermis. 
Marks reported that dermal wounds treated with collagen sponge seeded with fibroblasts or coated with bFGF show an increased level of reepithelialization, indicating that this method facilitates early dermal and epidermal wound healing. $\left.{ }^{44} 45\right)$ Consequently, this method improves complex wounds and quickly prepares a favorable wound bed (Figures 20, 21).
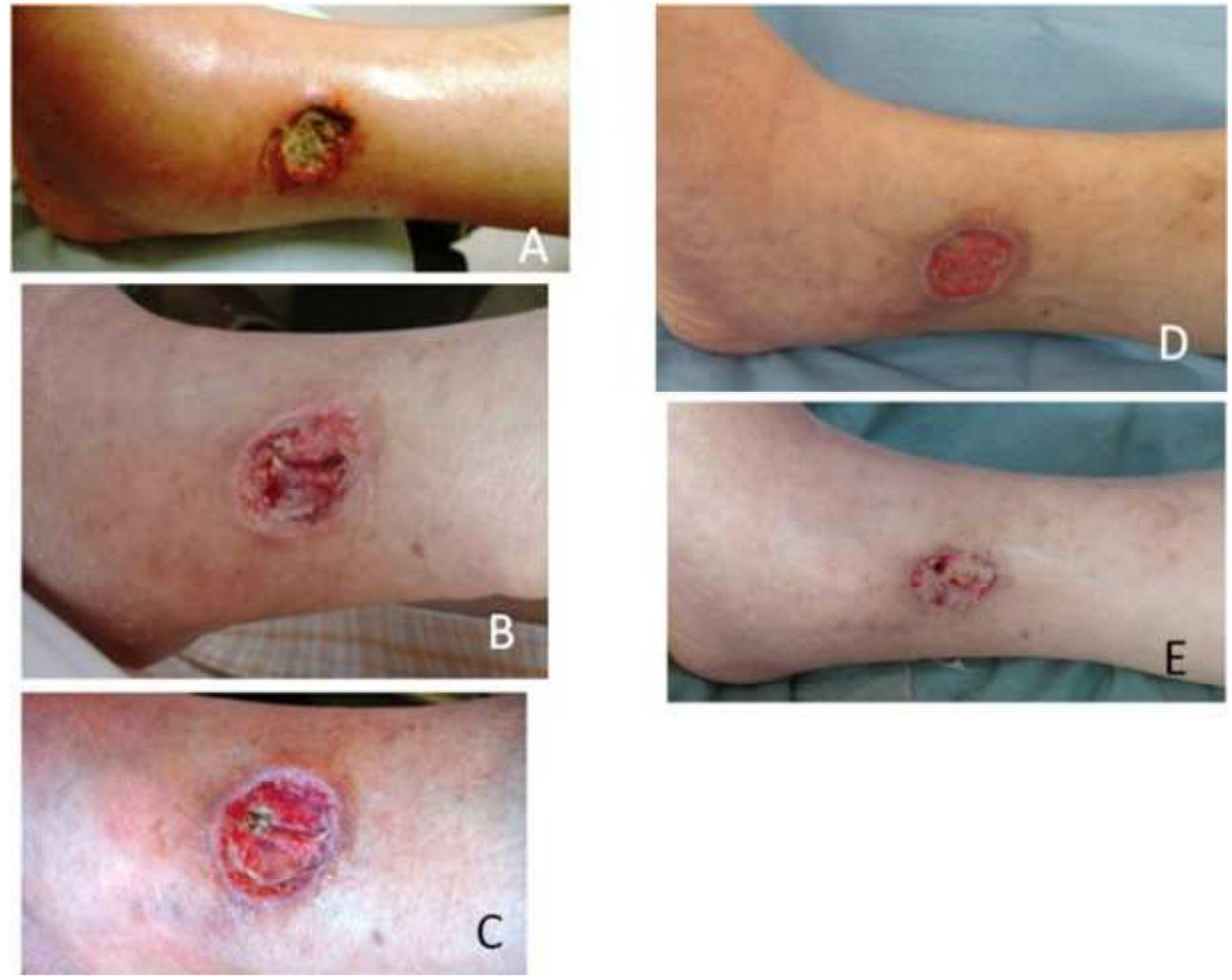

Fig. 20. (A) The photograph shows an unsatisfactory wound bed in a patient receiving HD because of DM at the initial examination. (B) A favorable wound bed did not develop, although cleansing and wet-to-dry dressing were continued for 2 weeks after debridement. (C) The wound became clean and a wound bed had developed 2 weeks after the start of combination treatment using bFGF and artificial dermis. (D) A favorable wound bed was prepared after 3 weeks of combination treatment. (E) The resurfaced wound 2 weeks after skin grafting. 

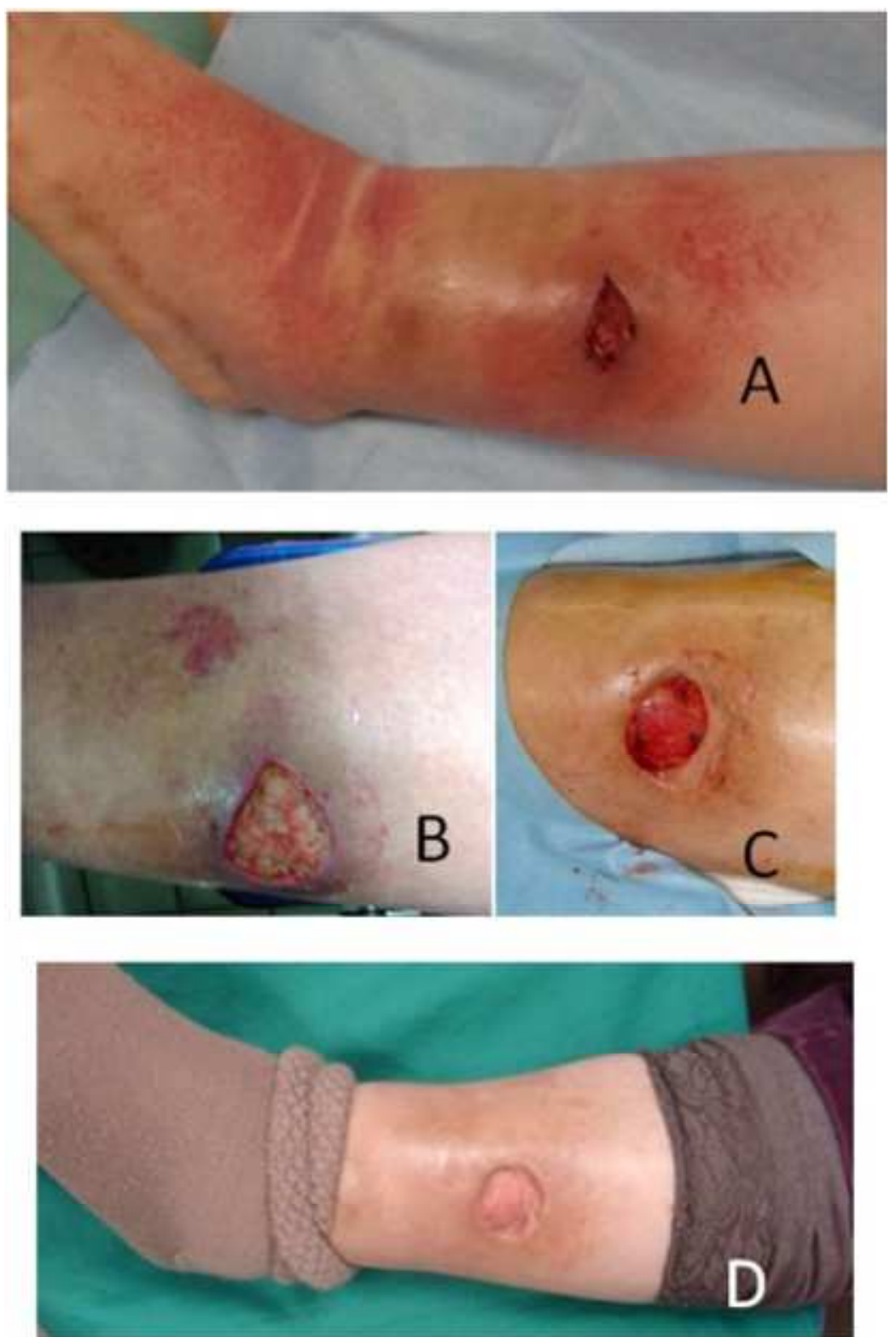

Fig. 21. (A) The photograph shows an infected wound in a patient receiving HD because of $\mathrm{DM}$ at the initial examination. (B) A favorable wound bed did not develop, although cleansing and wet-to-dry dressing were continued for 2 weeks after debridement. (C) The wound became clean and favorable for free skin grafting 2 weeks after the start of combination treatment using bFGF and artificial dermis. (D) The resurfaced wound 2 months after skin grafting. 
Thirdly, negative pressure using a vacuum system has been proposed for speeding up treatment. A negative pressure wound therapy (NPWT) system is emerging as an acceptable option in patients with non-healing wounds of the foot, ankle, and lower limb ${ }^{46}$. Negative pressure wound therapy is a technique used to promote healing in acute or chronic wounds. A vacuum source is used to create sub-atmospheric pressure $(125 \mathrm{~mm} \mathrm{Hg})$ in the local wound environment 47,48 ). A dressing, containing a drainage tube, is fitted to the contours of the wound and sealed with a transparent film. The tube is connected to a vacuum source, turning an open wound into a controlled, closed wound while removing excess fluid from the wound bed to enhance circulation and remove waste from the lymphatic system (Figure 22) ${ }^{49)}$. It could be used effectively to prepare ulcers for closure via split-skin grafting or secondary closure in good time. We usually perform wound bed preparation with a combination of these therapies for improved clinical treatment of complex wounds (Figures 23), 24).

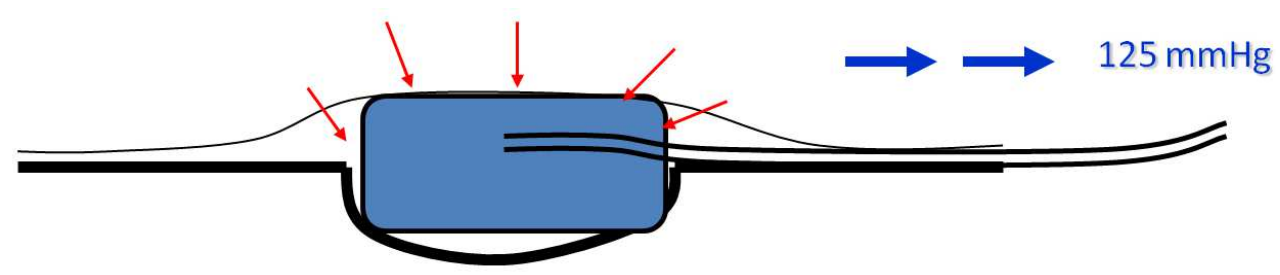

Fig. 22. Treatment of a full-thickness skin defect ulcer using artificial dermis.
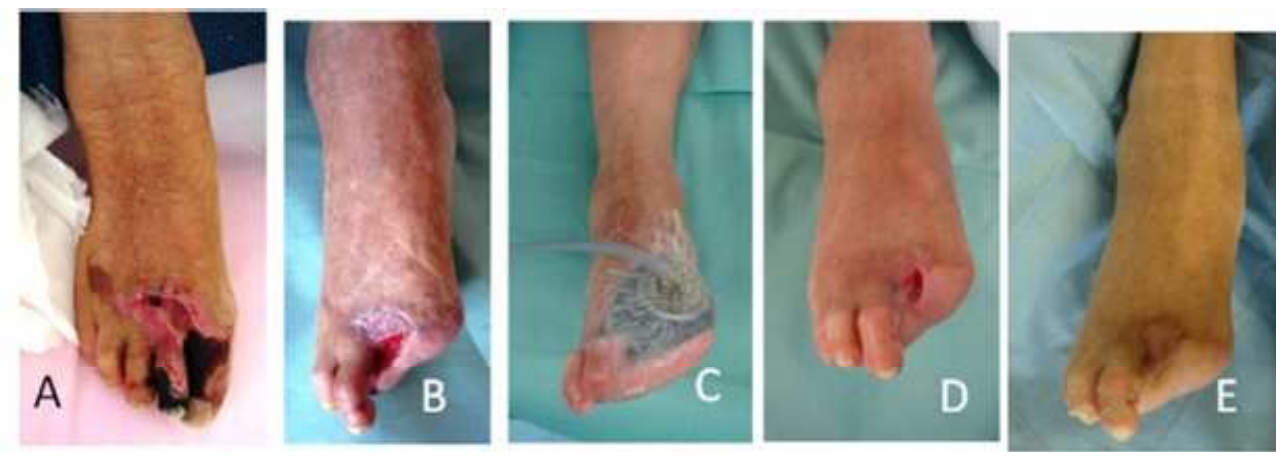

Fig. 23. (A) The photograph shows a necrotic wound of toes 1-3 in a patient receiving HD because of DM at the initial examination. He was also diagnosed ASO. He underwent amputation of toes 1-3, and the wound was sutured. (B) However, he developed a complex ulcer because of wound dehiscence. (C) Negative pressure wound therapy was performed. (D) Wound contraction was noted 2 weeks later. (E) The wound bed had closed completely 1 month later. 

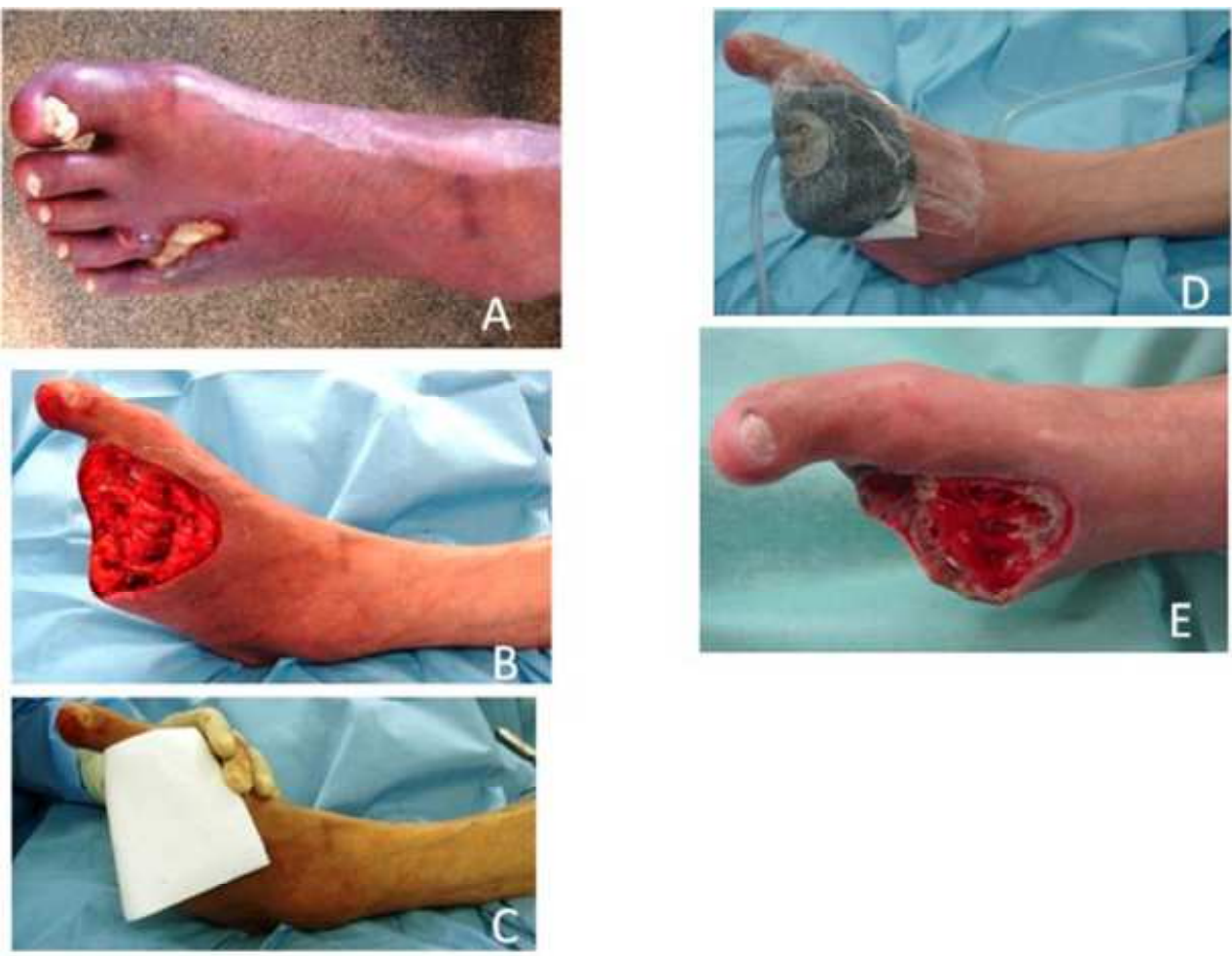

Fig. 24. (A) The photograph shows a complex wound in a patient receiving HD because of $\mathrm{DM}$ at the initial examination. He was also diagnosed with ASO. (B) He underwent amputation of toes 2-5, and the metacarpal bones were exposed. (C) Artificial dermis was applied on the wound. (D) Combined treatment of negative pressure wound therapy and artificial dermis was performed. (E) A favorable wound bed was prepared after 3 weeks of this combination treatment.

\section{Conclusion}

Patients receiving HD because of DM are likely to show more severe and rapidly developing complex wounds. They usually require immediate debridement before blood access shunts become infected.

\section{References}

[1] Akita S, Akino K, Imaizumi T, et al. The quality of pediatric burn scars is improved by early administration of basic fibroblast growth factor.J Burn Care Res. 2006;27:3338.

[2] Attinger CE, Janis JE, Steinberg J, Schwartz J, Al-Attar A, Couch K.Clinical approach to wounds: débridement and wound bed preparation including the use of dressings and wound-healing adjuvants. Plast Reconstr Surg. 2006 Jun;117(7 Suppl):72S-109S. 
[3] Bencini PL, Montagnino G, Citterio A, Graziani G, Crosti C, Ponticelli C. Cutaneous abnormalities in uremic patients. Nephron 1985;40:316-21.

[4] Bergesio F, Ciuti R, Salvadori M,et al.Are lipid abnormalities reliable cardiovascular risk factors in dialysis patients? Int J Artif Organs. 1989;12:677-682.

[5] Bird C.Managing malignant fungating wounds.Prof Nurse. 2000 ;15:253-256.

[6] Clare MP, Fitzgibbons TC, McMullen ST, Stice RC, Hayes DF, Henkel L. Experience with the vacuum assisted closure negative pressure technique in the treatment of nonhealing diabetic and dysvascular wounds.

[7] Deery HG 2nd, Sangeorzan JA. Saving the diabetic foot with special reference to the patient with chronic renal failure. Infect Dis Clin North Am. 2001;15:953-981.

[8] Douglass J.Wound bed preparation: a systematic approach to chronic wounds. Br J Community Nurs 2003;8:26-34.

[9] Dowsett C, Ayello E.TIME principles of chronic wound bed preparation and treatment. Br J Nurs. 2004 Aug 12-Sep 8;13(15):S16-23.

[10] Dyachenko P, Shustak A, Rozenman D.Hemodialysis-related pruritus and associated cutaneous manifestations. Int J Dermatol 2006;45:664-667.

[11] Ferreira MC, Carvalho VF, Kamamoto F, Tuma P Jr, Paggiaro AO. Negative pressure therapy (vacuum) for wound bed preparation among diabetic patients: case series. Sao Paulo Med J. 2009;127(3):166-70.

[12] Fujioka M, Fujii T. Maxillary growth following atelocollagen implantation on mucoperiosteal denudation of the palatal process in young rabbits: implications for clinical cleft palate repair. Cleft Palate Craniofac J. 1997;34:297-308.

[13] Fujioka Masaki, Oka Kiyoshi, Kitamura Riko, Yakabe Aya. Complex wounds tend to develop more rapidly in patients receiving hemodialysis because of diabetes mellitus Hemodial Int. Apr;13(2):168-71. 2009

[14] Fujioka Masaki, Oka Kiyoshi, Kitamura Riko, Yakabe Aya. Complex wounds tend to develop more rapidly in patients receiving hemodialysis because of diabetes mellitus Hemodial Int. 2009.Apr;13(2):168-71.

[15] Fujioka Masaki. Combination treatment with basic fibroblast growth factor and artificial dermis improves complex wounds caused by collagen diseases with steroid use. Dermatologic Surgery2009;35(9):1422-5.

[16] Fujioka Masaki.Artificial dermis: A new material for wound treatment.JOURNAL OF WOUND TECHNOLOGY. No. 4 APRIL 13-19.2009

[17] Hajheydari Z, Makhlough A.Cutaneous and mucosal manifestations in patients on maintenance hemodialysis: a study of 101 patients in Sari, Iran.Iran J Kidney Dis. 2008 Apr;2(2):86-90

[18] Hajheydari Z, Makhlough A.Cutaneous and mucosal manifestations in patients on maintenance hemodialysis: a study of 101 patients in Sari, Iran.Iran J Kidney Dis. 2008 Apr;2(2):86-90)

[19] Ibels LS, Stewart JH, Mahony JF, Neale FC, Sheil AG.Occlusive arterial disease in uraemic and haemodialysis patients and renal transplant recipients. A study of the incidence of arterial disease and of the prevalence of risk factors implicated in the pathogenesis of arteriosclerosis.Q J Med. 1977;46:197-214.

[20] Iseki.K. Pharmacological control of secondary hyperparathyroidism in chronic hemodialysis patients: cinacalcet is coming to Japan.Expert Opin Pharmacother 2008;9:601-610. 
[21] Jeanneret B, Magerl F. Treatment of osteomyelitis of the spine using percutaneous suction/irrigation and percutaneous external spinal fixation.J Spinal Disord. 1994 Jun;7(3):185-205.

[22] Kawamura A, Horie T, Tsuda I,et al.Clinical study of therapeutic angiogenesis by autologous peripheral blood stem cell (PBSC) transplantation in 92 patients with critically ischemic limbs.J Artif Organs. 2006;9:226-233.

[23] Lai MY, Lin YP, Yang WC.Fever with fulminant skin necrosis and digital gangrene in a uraemic woman.Nephrol Dial Transplant. 2007 May;22(5):1473-4.

[24] Lai MY, Lin YP, Yang WC.Fever with fulminant skin necrosis and digital gangrene in a uraemic woman.Nephrol Dial Transplant. 2007 May;22(5):1473-4.

[25] Marks MG, Doillon C, Silver FH. Effects of fibroblasts and basic fibroblast growth factor on facilitation of dermal wound healing by type I collagen matrices.J Biomed Mater Res. 1991 ;25:683-96.

[26] Mistik S, Utas S, Ferahbas A, et al An epidemiology study of patients with uremic pruritus. J Eur Acad Dermatol Venereol 2006;20:672-678

[27] Mistrík E, Dusilová-Sulková S, Bláha V, Sobotka L.Plasma albumin levels correlate with decreased microcirculation and the development of skin defects in hemodialyzed patients.Nutrition. 2010 Sep;26(9):880-5.

[28] Mistrík E, Dusilová-Sulková S, Bláha V, Sobotka L.Plasma albumin levels correlate with decreased microcirculation and the development of skin defects in hemodialyzed patients.Nutrition. 2010Sep;26(9):880-5.

[29] Nakase H, Matsuda R, Tamaki R, Tei R, Park YS, Sakaki T. Two-stage management for vertebral osteomyelitis and epidural abscess: technical note.Neurosurgery. 2006 Jun;58(6):1219.

[30] Nather A, Chionh SB, Han AY, Chan PP, Nambiar A. Foot Ankle Int. 2002 Oct;23(10):896-901.

[31] Nather A, Chionh SB, Han AY, Chan PP, Nambiar A.Effectiveness of vacuum-assisted closure (VAC) therapy in the healing of chronic diabetic foot ulcers. Ann Acad Med Singapore. 2010 May;39(5):353-8.

[32] Nease C. Using low pressure, NPWT for wound preparation \& the management of split-thickness skin grafts in 3 patients with complex wound. Ostomy Wound Manage. 2009 Jun 1;55(6):32-42.

[33] Noordzij M, Boeschoten EW, Bos WJ, Dekker FW, Bossuyt PM, Krediet RT, Korevaar JC; for the NECOSAD Study Group.Disturbed mineral metabolism is associated with muscle and skin complaints in a prospective cohort of dialysis patients.Nephrol Dial Transplant. 2007 Oct;22(10):2944-9. Epub 2007 Jun 27.

[34] Palmer-Kazen U, Wariaro D, Luo F, et al. Vascular endothelial cell growth factor and fibroblast growth factor 2 expression in patients with critical limb ischemia. J Vasc Surg. 2004; 39: 621-8.

[35] Panuncialman J, Falanga V .The science of wound bed preparation.Surg Clin North Am. 2009 Jun;89(3):611-26.

[36] Patel MS, Malinoski DJ, Nguyen XM, Hoyt DB.The impact of select chronic diseases on outcomes after trauma: a study from the National Trauma Data Bank.J Am Coll Surg. 2011 Jan;212(1):96-104.

[37] Pico MR, Lugo-Somolinos A. Cutaneous alterations in patients with chronic renal failure. Int J Dermatol 1992;31:860-3. 
[38] Pisoni RL, Wikstrom B, Elder SJ, Akizawa T, Asano Y, Keen ML, et al. Pruritus in haemodialysis patients: international results from the Dialysis Outcomes and Practice Patterns Study (DOPPS). Nephrol Dial Transplant 2006; 21: 3495-3505.

[39] Razeghi E, Omati H, Maziar S, Khashayar P, Mahdavi-Mazdeh M.Chronic inflammation increases risk in hemodialysis patients.Saudi J Kidney Dis Transpl. 2008 Sep;19(5):785-9.

[40] Robinson-Boston L, DiGiovanna JJ. Cutaneous Manifestations of end-stage renal descase. J Am Acad Dermatol. 2000;43:975-86.

[41] Schultz GS, Barillo DJ, Mozingo DW, Chin GA; Wound Bed Advisory Board Members. Wound bed preparation and a brief history of TIME.Int Wound J. 2004 Apr;1(1):1932.

[42] Schultz GS, Sibbald RG, Falanga V, Ayello EA, Dowsett C, Harding K, Romanelli M, Stacey MC, Teot L, Vanscheidt W.Wound bed preparation: a systematic approach to wound management.Wound Repair Regen. 2003 Mar;11 Suppl 1:S1-28.

[43] Stein, A. A. and Wiersum, J.: The Role of Renal Dysfunction in Abdominal Wound Dehiscence.J. Urol., 82:271, 1959.

[44] Stojadinovic A, Carlson JW, Schultz GS, Davis TA, Elster EA. Topical advances in wound care. Gynecol Oncol. 2008 Nov;111(2 Suppl):70-80.

[45] Suzuki S, Kawai K, Ashoori F, et al. Long-term follow-up study of artificial dermis composed of outer silicone layer and inner collagen sponge. Br J Plast Surg. 2000; 53: 659-66.

[46] Udayakumar P, Balasubramanian S, Ramalingam KS, Lakshmi C, Srinivas CR, Mathew AC.Cutaneous manifestations in patients with chronic renal failure on hemodialysis.Indian J Dermatol Venereol Leprol. 2006 Mar-Apr;72(2):119-25.

[47] Wikström B. Itchy skin--a clinical problem for haemodialysis patients.Nephrol Dial Transplant. 2007 Jul;22 Suppl 5:v3-7.

[48] Yasuhara $H$, Naka $S$, Yanagie $H$, Nagawa $H$. Influence of diabetes on persistent nonhealing ischemic foot ulcer in end-stage renal disease.World J Surg. 2002;26:1360-1364.

[49] Yosipovitch G, Duque MI, Patel TS, Ishiuji Y, Guzman-Sanchez DA, Dawn AG, Freedman BI, Chan YH, Crumrine D, Elias PM.Skin barrier structure and function and their relationship to pruritus in end-stage renal disease.Nephrol Dial Transplant. 2007 Nov;22(11):3268-72. 


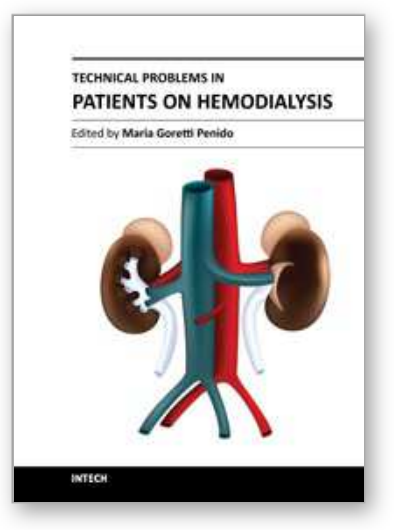

\author{
Technical Problems in Patients on Hemodialysis \\ Edited by Prof. Maria Goretti Penido
}

ISBN 978-953-307-403-0

Hard cover, 312 pages

Publisher InTech

Published online 07, December, 2011

Published in print edition December, 2011

This book provides an overview of technical aspects in treatment of hemodialysis patients. Authors have contributed their most interesting findings in dealing with hemodialysis from the aspect of the tools and techniques used.Each chapter has been thoroughly revised and updated so the readers are acquainted with the latest data and observations in the area, where several aspects are to be considered. The book is comprehensive and not limited to a partial discussion of hemodialysis. To accomplish this we are pleased to have been able to summarize state of the art knowledge in each chapter of the book.

\title{
How to reference
}

In order to correctly reference this scholarly work, feel free to copy and paste the following:

Masaki Fujioka (2011). Complex Wounds in Patients Receiving Hemodialysis, Technical Problems in Patients on Hemodialysis, Prof. Maria Goretti Penido (Ed.), ISBN: 978-953-307-403-0, InTech, Available from: http://www.intechopen.com/books/technical-problems-in-patients-on-hemodialysis/complex-wounds-inpatients-receiving-hemodialysis

\section{INTECH}

open science | open minds

\section{InTech Europe}

University Campus STeP Ri

Slavka Krautzeka 83/A

51000 Rijeka, Croatia

Phone: +385 (51) 770447

Fax: +385 (51) 686166

www.intechopen.com

\section{InTech China}

Unit 405, Office Block, Hotel Equatorial Shanghai

No.65, Yan An Road (West), Shanghai, 200040, China

中国上海市延安西路65号上海国际贵都大饭店办公楼 405 单元

Phone: +86-21-62489820

Fax: +86-21-62489821 
(C) 2011 The Author(s). Licensee IntechOpen. This is an open access article distributed under the terms of the Creative Commons Attribution 3.0 License, which permits unrestricted use, distribution, and reproduction in any medium, provided the original work is properly cited. 